\title{
Guideline for Optical Optimization of Planar Perovskite Solar Cells
}

Mehmet Koç ${ }^{1,2,3}$, Wiria Soltanpoor ${ }^{1,2,5}$,Gence Bektaş ${ }^{1,2}$, Henk J. Bolink ${ }^{5}$, Selçuk Yerci $^{1,2,4, *}$

${ }^{1}$ The Center for Solar Energy Research and Applications (GÜNAM), Ankara, Turkey

${ }^{2}$ Micro and Nanotechnology Department, Middle East Technical University, Ankara, Turkey

${ }^{3}$ Department of Electrical and Electronics Engineering, Ankara Ylldırım Beyazıt University, Ankara, Turkey

${ }^{4}$ Department of Electrical and Electronics Engineering, Middle East Technical University, Ankara, Turkey

${ }^{5}$ Instituto de Ciencia Molecular, Universidad de Valencia, C/Cat. J. Beltran 2, 46980 Paterna, Spain

*syerci@metu.edu.tr

\begin{abstract}
Organometallic halide perovskite solar cells have emerged as a versatile photovoltaic technology with soaring efficiencies. Planar configuration in particular, has been a structure of choice thanks to its lower temperature processing, compatibility with tandem solar cells and potential in commercialization. Despite all the breakthroughs in the field, the optical mechanisms leading to highly efficient perovskite solar cells lack profound insight. In this paper, a comprehensive guideline is introduced involving semi-analytical equations for thickness optimization of the front and rear transport layers, perovskite, and transparent conductive oxides to improve the antireflection and light trapping properties, and therefore to maximize the photocurrent of perovskite solar cells. It is shown that a photocurrent enhancement above $2 \mathrm{~mA} / \mathrm{cm}^{2}$ can be achieved by altering - reducing or increasing - the thicknesses of the layers constituting a $\mathrm{CH}_{3} \mathrm{NH}_{3} \mathrm{PbI}_{3}$ (MAPI) type perovskite solar cell. The proposed guideline is tested against experiments as well as previously published experimental and simulation results for MAPI. Additionally, the provided guideline for various types of perovskites can be extended to other direct band gap absorber-based solar cells in superstrate configuration.
\end{abstract}




\section{Introduction}

A new record efficiency has been announced for perovskite solar cells on average twice a year since 2013 thanks to their excellent optoelectronic properties such as high absorption coefficient and carrier mobilities, and long minority carrier lifetimes. ${ }^{[1-5]}$ Vast amount of research has been conducted on further improving stability and increasing the efficiency of perovskite solar cells. One way of boosting the efficiency of perovskite solar cells is maximizing the photocurrent generation by light management. Light management in perovskite solar cells can be provided by surface texturing, ${ }^{[6-13]}$ plasmonics, ${ }^{[14-16]}$ antireflective films on the glass substrate, ${ }^{[17,18]}$ vertical cavity design, ${ }^{[19-26]}$ and photon recycling. ${ }^{[27,28]}$ Among them, vertical cavity design is popular since it does not require any additional material other than what is needed to fabricate a perovskite solar cell, guaranteeing its low-cost.

Ball et al. reported optical simulation of glass/FTO (Fluorine-doped tin oxide) $/ \mathrm{TiO}_{2} / \mathrm{CH}_{3} \mathrm{NH}_{3} \mathrm{PbI}_{3}$ (MAPI)/Spiro-OMeTAD/Au solar cell structure based on transfer matrix method, where they reported local maxima in the modelled short circuit current at MAPI thicknesses of $\sim 190 \mathrm{~nm}, \sim 320 \mathrm{~nm}, \sim 470 \mathrm{~nm}$ and $\sim 630 \mathrm{~nm}$ thanks to favorable interference conditions. ${ }^{[21]}$ However, they did not extend their simulations to cover transport materials (TLs) with different refractive indices. In a recent study, Grant et al. published a comprehensive optical simulation study on MAPI/silicon tandem solar cells using the finite element method. ${ }^{[25]}$ They divided the ideal refractive index of a front transport layer (FTL) of the perovskite top solar cell into two regions: those larger and smaller than the refractive index of MAPI at $1000 \mathrm{~nm}$ of wavelength. However, this separation is incapable of explaining single junction perovskite solar cells targeting shorter wavelengths. Filipic et al. provided vertical cavity designs for 2- and 4- terminal- (2T and 4T) MAPI/silicon tandem solar cells in which, MAPI solar cell is composed of glass, front ITO (Indium Tin Oxide), Spiro-OMeTAD, $\mathrm{CH}_{3} \mathrm{NH}_{3} \mathrm{PbI}_{3}, \mathrm{TiO}_{2}$ and rear ITO layers. ${ }^{[23]}$ It is important to note that optimum thickness of a 
transport layer changes based on $2 \mathrm{~T}$ and $4 \mathrm{~T}$ configurations since in $2 \mathrm{~T}$ configuration nonoptimum layer thicknesses can lead to a photocurrent reduction in the perovskite top cell and its increase in the silicon bottom cell. Therefore, an optical cavity design of a perovskite solar cell resembles that of perovskite top cell in a 4T tandem cell geometry, yet, the effect of replacing the rear solar cell with a planar metal is optically substantial. Although an FTL refractive index $\left(n_{F T L}\right)$ around that of perovskite is commonly suggested in the literature, ${ }^{[20,25]}$ there is no comprehensive study on elucidation of the optical mechanism behind this suggestion.

Single layer homogeneous anti-reflective coating (ARC) is typically utilized in standard $\mathrm{Si}$ solar cells. It provides zero reflection at a single wavelength when a non-absorbing coating with a refractive index $\left(n_{\text {coat }}\right)$ satisfies the single layer ARC condition $\left(n_{\text {coat }}=\right.$ $\left.\sqrt{n_{\text {substrate }} \times n_{\text {medium }}}\right)$ and a thickness $\left(d_{\text {coat }}\right)$ equal to $\lambda / 4 n_{\text {coat }}$ called quarter-wave optical thickness (QWOT) is used. Additionally, multilayered ARCs can be used to suppress reflectance. In a perovskite solar cell, the front layers (FTL and transparent conductive oxide, TCO) can be designed to function as a double-layer ARC. In fact, a careful selection of refractive index and thickness of FTL can reduce light reflection and help trapping light inside the perovskite layer at the same time.

In this study, we first investigated ARC performance of the FTL in MAPI solar cells, by assuming a semi-infinite MAPI layer. Then, we elucidated the effects of thickness and refractive index of the FTL on light trapping by investigating three FTLs (PEDOT:PSS, $\mathrm{NiO}_{\mathrm{x}}$ and $\mathrm{TiO}_{2}$ ) with distinctive refractive index spectra and hypothetical FTLs with constant refractive indices. We provided an optical design guideline with sets of semi-analytical and empirical equations that allows one to predict the optimum thicknesses of MAPI, FTL and RTL (rear transport layer). While we utilized exemplary ITO and MAPI refractive index spectra, ${ }^{[20]}$ the effects of the use of alternative TCO materials and perovskites with different 
refractive indices are also discussed. We validated the developed models by fabricating MAPI solar cells with different MAPI thicknesses supporting QWOT and HWOT (half wave optical thickness) conditions at long wavelengths.

\section{Results and Discussion}

Maximum achievable photocurrent (MAPC) of a perovskite solar cell given in Equation 1, is used throughout the paper as a yardstick to evaluate the optical designs leading to the minimum reflection and parasitic losses, and therefore the highest expected short circuit current.

$$
M A P C=J_{p h} \cong q \int_{\lambda} \varphi(\lambda) A(\lambda) d \lambda
$$

where $q$ is the unit charge, $\varphi$ is the photon flux of the A.M. 1.5 spectrum, $A$ is the absorption spectrum of the perovskite layer. Therefore, MAPC indicates photocurrent of a solar cell assuming a unity internal quantum efficiency.

Figure 1a illustrates MAPC as a function of the refractive index and thickness of a hypothetical FTL. MAPI is assumed semi-infinite to investigate the reflection and parasitic absorption losses specific to FTL and ITO, and therefore to elucidate the anti-reflective performance of these layers. The refractive index of the FTL is assumed to be constant and its extinction coefficient is set as zero over the spectrum of interest to provide a straightforward guideline for the FTL optimization, leading to superior ARC performance in MAPI solar cells. Constant refractive index assumption is in good agreement with most of the transport materials such as $\mathrm{NiO}_{x}, \mathrm{TiO}_{2}$ and PEDOT:PSS whose refractive index spectra are shown in Figure 1b. An ITO thickness of $70 \mathrm{~nm}$ satisfying the QWOT condition at a wavelength around $525 \mathrm{~nm}$ is assumed in Figure 1a. Note that almost all TCO materials have near optimum refractive indices (i.e. $n_{\text {ITO }} \simeq \sqrt{n_{\text {substrate }} \times n_{\text {medium }}}$ ), allowing reflection reduction in the QWOT condition, in the absence of an FTL. While MAPC reduces with ITO thickness due to parasitic absorption, its dependence on the refractive index and thickness of 
the hypothetical FTL changes marginally with ITO thickness as shown in Figure SI-1a and SI-1b (Supporting Information).

There are three notable regions on Figure 1a, (see also Figure SI-1c for a wider FTL thickness range) where MAPC has distinct behaviors. 1) $n_{F T L}$ ranging between approximately 1.8 and 2.8 is optimum regardless of its thickness. 2) The optimum refractive index window widens for thinner FTLs. Particularly, MAPC becomes nearly independent of $n_{F T L}$ for thicknesses below $15 \mathrm{~nm}$. 3) MAPC strongly depends on FTL thickness when $n_{F T L}$ is not within the optimum range, leading to pronounced interferences within the FTL. For $n_{F T L}$ larger than 2.8 or smaller than 1.8, high and low reflections are obtained when QWOT and HWOT conditions are satisfied, respectively. For instance, HWOT conditions are satisfied if FTL thickness is in the ranges of $200-300 \mathrm{~nm}$ and 70-100 $\mathrm{nm}$ for small and large $n_{F T L}$, respectively. Conversely, when the thickness of FTL satisfies QWOT condition (e.g. FTL thicknesses ranges are $60-130 \mathrm{~nm}$ and $30-60 \mathrm{~nm}$ for small and large $n_{F T L}$, respectively), reflection increases which in turn, lowers the MAPC. The ranges of thicknesses are given considering the broadband nature of the solar spectrum. Otherwise, QWOT and HWOT selections should correspond to a single wavelength. As a result, the optimum FTL thickness is near zero when $n_{F T L}$ is larger than 2.8 and smaller than 1.8 as indicated by the solid line in Figure SI-1b. The optimum FTL thickness value drops from $\sim 97 \mathrm{~nm}$ to $\sim 16 \mathrm{~nm}$ when $n_{F T L}$ increases from 1.8 to 2.8 .

An ideal FTL should have a refractive index of 1.6 in the UV part of the spectrum as shown in Figure 1b. This number is near 2.0 in the IR part of the spectrum where refractive indices of MAPI and ITO are around 2.7 and 1.6, respectively. Finally, the refractive index of an ideal FTL should be around 2.5 in the visible part of the spectrum where the refractive index of ITO and extinction coefficient of MAPI is larger compared to their values in the IR part of the spectrum. An exemplary refractive index spectrum of an ideal FTL is shown in Figure 1b for a $30 \mathrm{~nm}$-thick FTL and $70 \mathrm{~nm}$-thick ITO providing a weighted reflection below $4.1 \%$ (i.e. 
below $0.6 \%$ when the reflection at the air/glass interface is ignored). In the rest of this study, we analyzed three commonly-used transport layers in perovskite solar cells: PEDOT:PSS, $\mathrm{NiO}_{\mathrm{x}}$, and $\mathrm{TiO}_{2}$, having distinctive refractive indices from each other as shown in Figure 1b. ${ }^{[29-31]}$ While the refractive index of $\mathrm{TiO}_{2}\left(n_{T i O 2}\right)$ is within the optimal refractive index window (Figure 1a), for almost all the spectrum of interest, that of PEDOT:PSS (nPEDOT:PSS) is mainly away the mentioned window. On the other hand, the refractive index of $\mathrm{NiO}_{\mathrm{x}}\left(n_{N i O x}\right)$ is near the lower limits of the optimum refractive index window for a wide portion of the spectrum of interest. It is important to note that while the refractive indices of PEDOT:PSS and ITO, and of $\mathrm{TiO}_{2}$ and MAPI pairs are similar, the refractive index of $\mathrm{NiO}_{\mathrm{x}}$ is nearly in between those of ITO and MAPI at long wavelengths.

The variation of MAPC of a semi-infinite MAPI with the ITO and FTL thicknesses - FTLs being PEDOT:PSS, $\mathrm{NiO}_{x}$ or $\mathrm{TiO}_{2}$ - is shown in Figure 2. The optimum ITO thickness range is 50-70 $\mathrm{nm}$ in the absence of an FTL (Figure 2), ${ }^{[9,23,26]}$ satisfying the QWOT condition. Moreover, MAPC gradually reduces with the ITO, PEDOT:PSS, $\mathrm{TiO}_{2}$ and $\mathrm{NiO}_{\mathrm{x}}$ thicknesses due to the parasitic absorptions in these layers as their extinction coefficients are non-zero, notably at short wavelengths. MAPC increases with decreasing PEDOT:PSS thickness and maximizes in its absence as shown in Figure 2a, and as suggested in Figure 1a. Additionally, the local maximum around a PEDOT:PSS thickness of $160 \mathrm{~nm}$ is due to the satisfied HWOT condition at a central wavelength around $500 \mathrm{~nm}$. It should be noted that a PEDOT:PSS thickness of $160 \mathrm{~nm}$ is too-thick for efficient carrier transport. On the other hand, MAPC does not alter significantly with $\mathrm{TiO}_{2}$ thickness since its refractive index especially for wavelengths longer than $475 \mathrm{~nm}$ is similar to that of MAPI (Figure 1b). Therefore, the $\mathrm{TiO}_{2}$ and MAPI layers act as one consolidated optical layer, and the reflection arisen from the $\mathrm{TiO}_{2} / \mathrm{MAPI}$ interface is the least significant. In addition, the refractive index of $\mathrm{TiO}_{2}$ is significantly larger than that of MAPI and its extinction coefficient is maximal at short wavelengths, leading to high reflection and parasitic absorption losses in this region of the spectrum. As a result, a 
maximal trend in MAPC occurs at a $\mathrm{TiO}_{2}$ thickness around $25 \mathrm{~nm}$ (Figure 2b), which provides a superior ARC efficiency at wavelengths around $400 \mathrm{~nm}-600 \mathrm{~nm}$ as shown in Figure SI-2a. MAPC also shows relatively small dependence on the thickness of $\mathrm{NiO}_{\mathrm{x}}$ (Figure 2c) since its refractive index lies within the optimum refractive index range across the absorption spectrum of MAPI as shown in Figure 1. MAPC maximizes when the sum of the thickness of ITO and $\mathrm{NiO}_{\mathrm{x}}$ is $60 \mathrm{~nm}$ (Figure 2c), presenting absorption maximum primarily at long wavelengths (>600 nm) as shown in Figure SI-2b. A wide range of $\mathrm{NiO}_{\mathrm{x}}$ thickness allows high MAPC since its refractive index is close to that of ITO, particularly, in the visible part of the spectrum, which results in low reflection at the interface of $\mathrm{NiO}_{\mathrm{x}}$ and ITO. It should be noted that $60 \mathrm{~nm}$ for $\mathrm{NiO}_{\mathrm{x}}$ and $25 \mathrm{~nm}$ for $\mathrm{TiO}_{2}$ as optimum thicknesses show great agreement with those obtained from the constant refractive index analysis, indicated by the solid line in Figure SI-1b, demonstrating a validation of this approach for metal oxides. The thickness selection of ITO is crucial not only from the optical perspective but also from the electrical point of view as it should be thick enough to provide the required lateral conductivity. Relatedly, a $210 \mathrm{~nm}$-thick ITO, having a typical sheet resistance of approximately $10 \Omega / \square$, was chosen in Figure $2 \mathbf{d}$ and the rest of the paper unless otherwise noted.

The absorption spectra of semi-infinite MAPI calculated for $30 \mathrm{~nm}$-thick PEDOT:PSS, $\mathrm{TiO}_{2}$ and $\mathrm{NiO}_{\mathrm{x}}$ are shown in Figure 2d along with AM1.5G photon flux spectrum. The highest absorption belongs to the case with PEDOT:PSS in the UV, and with $\mathrm{NiO}_{\mathrm{x}}$ and $\mathrm{TiO}_{2}$ in the visible and IR parts of the spectrum. In contrast with UV, there is a higher photon flux at longer wavelengths of $\mathrm{AM} 1.5 \mathrm{G}$ photon flux spectrum making $\mathrm{NiO}_{\mathrm{x}}$ and $\mathrm{TiO}_{2}$ mainly superior to PEDOT:PSS. The absorption drop in MAPI observed in wavelengths shorter than $350 \mathrm{~nm}$ for $\mathrm{NiO}_{\mathrm{x}}$ and $\mathrm{TiO}_{2}$ is mainly due to larger refractive index difference between the FTLs and MAPI, and larger parasitic absorption in the FTLs as shown in Figure SI-3. The dip in the absorption spectrum in the case of $\mathrm{NiO}_{\mathrm{x}}$ around $480 \mathrm{~nm}$ can be attributed to the fact that total 
combined optical thickness of $\mathrm{NiO}_{\mathrm{x}}$ and ITO is an integer multiple of HWOT. In the case of PEDOT:PSS, this dip shifts to $470 \mathrm{~nm}$ as a result of smaller optical thickness of PEDOT:PSS. Additionally, the dip is stronger in the case of PEDOT:PSS due to the larger refractive index difference between PEDOT:PSS and MAPI compared to that between $\mathrm{NiO}_{\mathrm{x}}$ and MAPI. In the case of $\mathrm{TiO}_{2}$ as FTL, absorption spectrum of MAPI is significantly improved for 420-600 nm by ARC performance of $\mathrm{TiO}_{2}$ for $30 \mathrm{~nm}$ thickness in coherence with Figure $\mathbf{2 b}$ and SI-2a. When PEDOT:PSS or $\mathrm{NiO}_{\mathrm{x}}$ hole transport layers are utilized at the front side of a MAPI solar cell (Figure 3a), PCBM is typically preferred as the electron transport layer at its rear side. Similarly, Spiro-OMeTAD is a common rear side hole transport layer when $\mathrm{TiO}_{2}$ is used at the front side as electron transport layer. Figure 3b shows the absorption spectra of $445 \mathrm{~nm}$ and $510 \mathrm{~nm}$-thick MAPIs for ITO, $\mathrm{NiO}_{x}$, PCBM and Ag thicknesses of 210, 30, 50 and 100 $\mathrm{nm}$, respectively. The absorption spectrum of a semi-infinite MAPI (i.e. $100 \mu \mathrm{m}$ ) with $30 \mathrm{~nm}$ thick $\mathrm{NiO}_{\mathrm{x}}$ and $210 \mathrm{~nm}$-thick ITO atop is also provided for comparison. Extinction coefficient of MAPI is maximum at a wavelength of around $350 \mathrm{~nm}$ and it gradually decreases with wavelength as shown in Figure 1b. Thus, depending on the thickness of MAPI, light at short wavelengths is typically absorbed before reaching the rear side of the solar cell. On the other hand, light at long wavelengths is dominantly absorbed in distinct fringes (the inset of Figure 3b) due to interferences. Therefore, the regions before and beyond a threshold wavelength are called Beer-Lambert and interference zones of the spectrum, respectively, as shown in Figure 3b. ${ }^{[19]}$ The onset of the interference region changes from a threshold wavelength of $420 \mathrm{~nm}$ to $630 \mathrm{~nm}$ for typical MAPI thicknesses of 250 and $800 \mathrm{~nm}$, respectively, as shown in Figure SI-4. A threshold wavelength around $550 \mathrm{~nm}$ is evident in Figure 3b for a MAPI thickness of $\sim 500 \mathrm{~nm}$.

Constructive and destructive interferences in perovskite have a predominant effect on MAPC making it maximum and minimum, respectively. ${ }^{[20,21]}$ While a $445 \mathrm{~nm}$-thick MAPI benefits from constructive interferences, a $510 \mathrm{~nm}$-thick one suffers from destructive interferences at 
long wavelengths (i.e. around 700-750 nm). As a result, a $445 \mathrm{~nm}$-thick MAPI yields 0.5 $\mathrm{mA} / \mathrm{cm}^{2}$ higher MAPC compared with a $510 \mathrm{~nm}$-thick one in the given cell configuration with $\mathrm{NiO}_{\mathrm{x}}$. It should be noted that a $0.5 \mathrm{~mA} / \mathrm{cm}^{2}$ increase in MAPC, using a thinner MAPI (455 nm vs. $525 \mathrm{~nm}$ for PEDOT:PSS and $435 \mathrm{~nm}$ vs. $510 \mathrm{~nm}$ for $\mathrm{TiO}_{2}$ ), can also be achieved in case of PEDOT:PSS and $\mathrm{TiO}_{2}$ as shown in Figure SI-5. Note that absorption in MAPI is limited at wavelengths longer than $780 \mathrm{~nm}$ (i.e. near its band edge) due to very low extinction coefficient of MAPI.

Figure 4a, $\mathbf{4 d}$ and $\mathbf{4 g}$ illustrate the effects of the thicknesses of the rear transport layer (RTL) and MAPI on MAPC when a 30 nm-thick PEDOT:PSS, $\mathrm{NiO}_{\mathrm{x}}$ or $\mathrm{TiO}_{2}$ is used as the FTL. Additionally, Figure 4b, 4e and $4 \mathrm{~h}$ demonstrate the effects FTL and MAPI thicknesses on MAPC when a 50 nm-thick RTL is used.

The optimum MAPI $\left(t_{M A P I}\right)$ and RTL thicknesses $\left(t_{R T L}\right)$ leading to local maxima in MAPC indicated by the dashed lines in Figure $\mathbf{4 a}$ and $\mathbf{4 b}$, are expressed by the following linear formula when the FTL is PEDOT:PSS.

$$
t_{M A P I} \cong 50+\left(\lambda_{o} / 2 n_{M A P I}\right) m-\left(n_{R T L} / n_{M A P I}\right) t_{R T L}
$$

where $m$ is an integer, representing the interference order, $n_{R T L}$ and $t_{R T L}$ are the refractive index and thickness of the RTL and $\lambda_{o}$ is a cutoff wavelength slightly smaller $(\sim 20 \mathrm{~nm})$ than absorption onset wavelength. The constructive interference patterns occur approximately at every $150 \mathrm{~nm}$ of the MAPI thickness satisfying HWOT condition at the wavelength of $\lambda_{o}=$ $770 \mathrm{~nm}$ as shown in Figure $\mathbf{4 a}$ and $\mathbf{4 b}$. Refractive indices of $n_{R T L}$ and $n_{M A P I}$ are selected at 770 $\mathrm{nm}$ (for $\mathrm{m}=3$ ), which is near the center-wavelength of strong interferences in MAPI. A slightly shorter $(\sim 730 \mathrm{~nm})$ or a longer center-wavelength $(\sim 780 \mathrm{~nm})$ can be selected for $\mathrm{m}=1$ or $m>3$, respectively, as the onset of the interference region changes with MAPI thickness as shown in Figure SI-4. The perfect fit of the Equation 2 with the maxima in MAPC shown in Figure 4a, indicates that the RTL acts as a phase shifter. Therefore, the optimal MAPI 
thickness for each interference order decreases with the RTL thickness due to the phase shift introduced by RTL as shown in Figure 4a.

The optimal PEDOT:PSS and MAPI thicknesses are optically decoupled from each other (Figure 4b) since the refractive indices of PEDOT:PSS, ITO and glass are contiguous in the interference region. Therefore, the propagated photons from MAPI into PEDOT:PSS are transmitted to the glass without being reflected back from the interfaces of PEDOT:PSS/ITO and ITO/glass. Thus, interferences in the MAPI solar cell at long wavelengths happen between MAPI/PEDOT:PSS and PCBM/Ag interfaces as illustrated in Figure 4c.

When the FTL is $\mathrm{TiO}_{2}$, a horizontal shift of the dashed lines in Figure 4d - compared to Figure 4a - and a prominent incline of the dashed lines towards y-axis in Figure 4e are observed. The magnitude of the shift and the slope of the inclination can be determined by subtracting the term $\left(n_{F T L} / n_{M A P I}\right) t_{F T L}$ from Equation 2. The resultant formula is given in Equation 3.

$$
t_{M A P I} \cong 50+\left(\lambda_{o} / 2 n_{M A P I}\right) m-\left(n_{R T L} / n_{M A P I}\right) t_{R T L}-\left(n_{F T L} / n_{M A P I}\right) t_{F T L}
$$

It should be noted that the shift is almost equal to the physical thickness of $\mathrm{TiO}_{2}$ since $n_{\mathrm{TiO} 2}$ is contiguous with $n_{M A P I}$ at wavelengths longer than $475 \mathrm{~nm}$ where the photon flux is superior in the AM $1.5 \mathrm{G}$ spectrum. For the same reason, the slope of the inclination is approximately $45^{\circ}$. Local maxima in MAPC happen as straight lines indicating that interferences in these solar cells occur between $\mathrm{TiO}_{2} / \mathrm{ITO}$ and PCBM/Ag interfaces as illustrated in Figure 4f. Superior ARC performance in $\mathrm{TiO}_{2}$ at short wavelengths, illustrated in Figure $4 \mathbf{f}$ by the straight arrow, lead to a local maxima at a $\mathrm{TiO}_{2}$ thickness of $25 \mathrm{~nm}$ as shown in Figure $\mathbf{2 b}$ and Figure SI-7b (the green arrow), and also appears in Figure 4e.

When $\mathrm{NiO}_{\mathrm{x}}$ is utilized as the FTL, similar to $\mathrm{TiO}_{2}$, a horizontal shift of the local maxima of MAPC with PCBM and MAPI thicknesses occurs (Figure 4g vs. Figure 4a). Unlike PEDOT:PSS and $\mathrm{TiO}_{2}$, the refractive index of $\mathrm{NiO}_{\mathrm{x}}$ in the interference zone is dissimilar to that of both ITO and MAPI. Therefore, interferences in MAPI - occurs when MAPI thickness obeys Equation 2 - can be supported or cancelled out when $\mathrm{NiO}_{\mathrm{x}}$ thickness satisfies $m \lambda / 2 n_{N i O x}$ 
or $(2 m+1) \lambda / 2 n_{N i O x}$ conditions, respectively, as illustrated in Figure 4i. As a result, maxima in MAPC can be achieved when both interferences take place constructively as shown in Figure 4h and SI-6. However, the highest values of MAPC occur not in the absence of $\mathrm{NiO}_{\mathrm{x}}$ but when the thickness of $\mathrm{NiO}_{\mathrm{x}}$ is equal to approximately $60 \mathrm{~nm}$ thanks to the superior ARC efficiency, particularly at long wavelengths, as shown in Figure $\mathbf{4 h}$ and $\mathbf{2 c}$ when a thick MAPI (>700 nm or $\mathrm{m}>5$ ) is used. A thinner $\mathrm{NiO}_{x}$, shown as the green arrow in Figure SI-7c, provides the optimum ARC performance for thinner MAPI layers, where IR light cannot be harnessed efficiently. The $\mathrm{NiO}_{\mathrm{x}}$ thickness satisfying QWOT condition $(95 \mathrm{~nm})$ at long wavelengths acts as the optimum $\operatorname{ARC}\left(\lambda / 4 n_{N i O x}\right)$ for light reflected from the rear metal contact. Therefore, relatively high MAPC can be extracted for almost any $\mathrm{NiO}_{\mathrm{x}}$ thickness between 0 and $100 \mathrm{~nm}$ as shown in Figure 4h.

As discussed through Figure 4, Equation 2 or 3 can be used if the interferences occur in between the MAPI/FTL and RTL/Ag interfaces or in between the FTL/ITO and RTL/Ag interfaces, respectively. It is worth discussing the accuracy of Equation $\mathbf{2}$ and $\mathbf{3}$ in predicting the thicknesses of MAPI and transport layers to attain local maxima in MAPC, and the validity of them with respect to $n_{F T L}, n_{T C O}$ and $n_{M A P I}$. Equation $\mathbf{2}$ and $\mathbf{3}$ are accurate within few nanometers according to the TMM simulations and published experimental results for PEDOT:PSS and $\mathrm{TiO}_{2}$ as shown in Figure SI-7a and SI-7b, respectively. ${ }^{[19-21]}$ In fact, Figure SI-8 shows that Equation $\mathbf{2}$ and $\mathbf{3}$ are valid when $n_{F T L}$ (assumed to be constant) is below and above 2.1, respectively. Note that extinction coefficient of FTL is assumed to be zero over the spectrum of interest in Figure SI-8. At the transition refractive index (i.e. $n_{F T L}=2.1$ ), the deviation in the optimum MAPI thickness from what is calculated by both equations is the largest as shown in Figure SI-8.

As discussed through Figure $\mathbf{4 e}$ and $\mathbf{4 h}$, while the optimum $\mathrm{NiO}_{\mathrm{x}}$ thickness decreases with MAPI thickness, $\mathrm{TiO}_{2}$ thickness does not change significantly. Additionally, the optimum PEDOT:PSS thickness should be zero regardless of the MAPI thickness. As a result, the 
effect of $n_{F T L}$ on the optimum thickness of FTL, and therefore on Equation 3 is intricate.

Figure SI-9 shows the optimum FTL thickness versus its refractive index for various thicknesses of MAPI, satisfying constructive interference at long wavelengths when RTL thickness is zero. The shaded areas in Figure SI-9 indicate FTL thickness range at which the MAPC changes less than $1 \%$ from its maxima at the calculated $n_{F T L}$ (shown by square symbols). Equation 4 is an empirical fit to Figure SI-9 for $n_{F T L}$ larger than $n_{\text {cut-off }}$, providing the optimum FTL thickness when the thicknesses of MAPI and RTL satisfy Equation 2 for interference orders larger than or equal to 2 (shown by solid red line in Figure SI-9).

Difference between computed optimum FTL thickness and Equation 4 predictions is less than $0.6 \mathrm{~nm}$. The optimum FTL thickness for thin MAPI solar cells with the interference order of 1 is zero as shown in Figure SI-9a. $n_{\text {cut-off }}$ is the transition refractive index at which the optimum FTL thickness is no longer zero.

$$
t_{F T L}=\left(t_{\text {semi-inf }}-t_{0} \times \exp \left(-t_{M A P I} / t_{1}\right)\right) \times \exp \left(-\left(n_{F T L}-n_{c u t-o f f}\right) \times C\right)
$$

where $C=C_{0}+C_{1} \exp \left(-t_{M A P I} / t_{2}\right), t_{\text {semi-inf }}=118.80 \mathrm{~nm}, t_{0}=167.65 \mathrm{~nm}, t_{1}=361.85 \mathrm{~nm}, C_{0}=1.71$, $C_{1}=4.04, t_{2}=170.77 \mathrm{~nm} . t_{\text {semi-inf }}$ is the optimum FTL thickness when MAPI thickness is semiinfinite and $n_{F T L}$ is $n_{\text {cut-off, }}$ which is equal to $1.95,1.85,1.80$ and 1.75 for MAPI interference orders of $2,3,4$ and $>=5$, respectively.

The wavelength at which the value of $n_{F T L}$ is selected can be taken as $450 \mathrm{~nm}$. However, for materials whose refractive index decreases with wavelength, $n_{F T L}$ at a shorter wavelength provides a superior prediction for the thickness of FTL. Additionally, one should target a smaller FTL thickness when FTLs with large extinction coefficient are used which might be unavoidable when $n_{F T L}>2.5$. Nevertheless, the optimum thickness deviations for $\mathrm{NiO}_{\mathrm{x}}$ and $\mathrm{TiO}_{2}$ from what is predicted by Equation 4 lead to less than $1 \%$ changes in MAPC from its maxima at the calculated $n_{F T L}$ as shown in Figure SI-9.

It should be noted that the thickness of ITO does not appear in Equation $\mathbf{2}$ and $\mathbf{3}$ since similar refractive indices of ITO and glass at long wavelengths hinder the formation of interferences 
within the ITO layers. In other words, MAPI thicknesses, where local maxima in MAPC for various interference orders occur, do not change with the ITO thickness as shown in Figure SI-10a. This can be generalized for other common TCO materials such as AZO (Aluminumdoped Zinc Oxide) and FTO (Fluorine-doped Indium Oxide) as shown in Figure SI-10b. Additionally, the variations in optimum MAPI thicknesses are within a range of $10 \mathrm{~nm}$ when the refractive index and extinction coefficient spectra of MAPI are altered as shown in Figure SI-10c. Yet, the amplitude of MAPC varies due to different extinction coefficients.

\section{Discussions}

Here, we propose a guideline to predict the optimal thicknesses of the layers in MAPI solar cells (TCO, FTL, MAPI and RTL) when the refractive indices of FTL (both at $450 \mathrm{~nm}$ and $770 \mathrm{~nm}$ ) and RTL (at $770 \mathrm{~nm}$ ) are known. The sets of equations that need to be used for this purpose are given in Table 1.

The optical engineering of a MAPI solar cells can be summarized as follows (also a decision tree is given in Figure SI-11 ).

1) Use an FTL with a refractive index between 1.8 and 2.8 (at $\lambda=450 \mathrm{~nm}$ ). Otherwise, use as thin FTL as possible. Then, the thicknesses of MAPI and RTL can be calculated using Equation 2 or 3 if $n_{F T L}<2.1$ ( $n_{\text {transition }}$ ) or $n_{F T L}>2.1$ at $770 \mathrm{~nm}$ wavelength, respectively. Note that a thinner RTL is preferable if its extinction coefficient is non-zero.

2) Calculate the approximate thicknesses of MAPI based on the thickness of the RTL using Equation 2. Note that there is about $150 \mathrm{~nm}$ MAPI thickness in between two consecutive constructive interferences. Decide the thickness of FTL using Equation 4 based on its refractive index (at $\lambda=450 \mathrm{~nm}$ ) and $t_{\text {MAPI. }}$. Recalculate $t_{\text {MAPI }}$ taking into account $t_{F T L}$ using Equation 3 if $n_{F T L}$ is above 2.1 (at $\lambda=770 \mathrm{~nm}$ ). Superior $t_{F T L}$ and $t_{M A P I}$ values can be found by iterating Equation 4 and 3. It should be noted that the optimum FTL thickness for very thin MAPI layers with the interference order of 1 is 
zero. Table SI-1 and Table SI-2 provide the optimum FTL and MAPI thicknesses calculated using the proposed guideline and reported in the literature.

3) The optically optimum ITO thickness is around $60 \mathrm{~nm}$. MAPC decreases monotonically with TCO thickness as a result of parasitic absorption. Therefore, TCO thickness should solely be decided taking the area of the solar cell into account.

4) Approximately $100 \mathrm{~nm} \mathrm{MgF} 2 \mathrm{ARC}$ on glass can provide an additional enhancement of $0.4 \mathrm{~mA} / \mathrm{cm}^{2}$ in MAPC as shown in Figure SI-12.

5) An RMS roughness of $15 \mathrm{~nm}$ does not affect the optimum thicknesses but can result in about $0.1 \mathrm{~mA} / \mathrm{cm}^{2}$ reduction in MAPC as shown in Figure SI-12.

The validity of the guidelines proposed in this work was investigated in device structures with $115 \mathrm{~nm}$-thick ITO, $33 \mathrm{~nm}$-thick $\mathrm{NiO}_{\mathrm{x}}$ as FTL, $25 \mathrm{~nm}$-thick $\mathrm{C}_{60} / 7 \mathrm{~nm}$-thick BCP as ETL and 100 nm-thick Ag. The refractive index profiles of ITO, $\mathrm{NiO}_{x}$, MAPI and $\mathrm{C}_{60}$ were successively measured by spectroscopic ellipsometry following the fabrication sequence. The measured spectra are given in Figure SI-13. The refractive index of BCP was acquired from literature. ${ }^{[32]}$ Co-evaporation method was utilized to precisely control the thickness of the MAPI. ${ }^{[33,34]}$ The cross-sectional SEM images of the fabricated devices are shown in the inset of Figure 5a. Based on the guideline given in this article, the interferences in $370 \mathrm{~nm}$-thick MAPI are destructive while those in $310 \mathrm{~nm}$ and $460 \mathrm{~nm}$-thick MAPI layers are constructive at long wavelengths. This is studied by replacing $A(\lambda)$ by $1-R(\lambda)$ in Equation 1 to calculate the total photocurrent shown in Figure 5a. Since the reflection $(\mathrm{R})$ measurements were performed on solar cells, the comparison between the simulation and experimental results are provided based on 1-R( $\lambda$. The experimental 1-R( $\lambda$ ) spectra for the mentioned thicknesses of MAPI are plotted in Figure 5b. They are alike in the range of $\lambda=300-550 \mathrm{~nm}$ and diverge in the interference region of $\lambda=550-800 \mathrm{~nm}$ as shown in Figure 5b. Constructive and destructive interferences for the optimum and non-optimum thicknesses appear as predicted. For instance, they result in lower 1-R $(\lambda)$ values in the case of the device with $370 \mathrm{~nm}$ MAPI. 
In sum, according to Figure 5, the trend in the calculated MAPC matches the measured 1-R $(\lambda)$ values of the chosen thicknesses of MAPI.

Figure 6a summaries MAPC, and reflection and parasitic absorption losses when A) nonoptimum thicknesses of MAPI, FTL and ITO, (B) optimum thicknesses of MAPI and FTL but non-optimum thickness of ITO, and C) optimum MAPI, FTL and ITO thicknesses are used. Moreover, the thickness of the layers constituting the MAPI solar cell for cases A, B and C and for the three FTL materials are given in Figure 6b. Ag thickness is set as $100 \mathrm{~nm}$ to guarantee that no light is transmitted. Besides, an RTL thickness of $50 \mathrm{~nm}$ is assumed. Reducing the PEDOT:PSS and MAPI thicknesses from $85 \mathrm{~nm}$ to $25 \mathrm{~nm}$ and from $520 \mathrm{~nm}$ to $455 \mathrm{~nm}$, respectively, lower the reflection and parasitic absorption losses, allowing a 1.8 $\mathrm{mA} / \mathrm{cm}^{2}$ higher MAPC. Also, a thinner ITO $(60 \mathrm{~nm}$ vs. $210 \mathrm{~nm})$ further reduces the reflection and parasitic losses, and therefore the MAPI solar cell can possess an addition MAPC of 0.62 $\mathrm{mA} / \mathrm{cm}^{2}$. Similarly, reducing the $\mathrm{TiO}_{2}$ and MAPI thicknesses from $90 \mathrm{~nm}$ to $20 \mathrm{~nm}$ and from $585 \mathrm{~nm}$ to $445 \mathrm{~nm}$, respectively, and using the optimum ITO thickness of $60 \mathrm{~nm}$ allow boosting the MAPC by $1.85 \mathrm{~mA} / \mathrm{cm}^{2}$. Finally, reducing the MAPI thickness from $520 \mathrm{~nm}$ to $445 \mathrm{~nm}$ and increasing $\mathrm{NiO}_{\mathrm{x}}$ thickness from $10 \mathrm{~nm}$ to $50 \mathrm{~nm}$ together with the optimum ITO thickness enhance the MAPC by $1.07 \mathrm{~mA} / \mathrm{cm}^{2}$.

The proposed guideline for MAPI can be generalized to be employed in other commonly-used perovskites with different compositions. Equation (2) and (3) can be re-written as

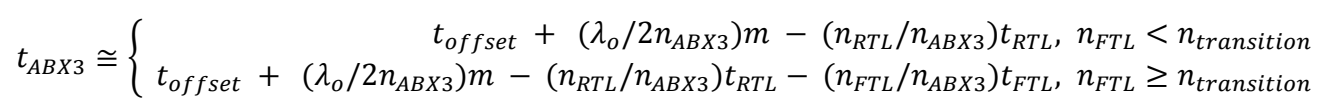

where $\lambda_{o}$ is slightly below the absorption onset wavelength of perovskite, $t_{o f f s e t}$ is the fitted offset thickness, $n_{A B X 3}$ is the refractive index of perovskite and $n_{F T L}$ is the refractive index of FTL at $\lambda_{o}$, and $n_{\text {transition }}$ is the transition refractive index where condition switches between cases. Values of $\lambda_{o}, n_{\text {transition }}$ and $t_{\text {offset }}$ for different types of perovskites are provided in Table

\section{SI-3.}


We tested the validity of Equation (5) by comparing the optimal perovskite thicknesses found by TMM simulations for various types of perovskites (Table SI-4). Perovskite $\left(\mathrm{Cs}_{0.17} \mathrm{FA}_{0.83} \mathrm{~Pb}\left(\mathrm{Br}_{0.17} \mathrm{I}_{0.83}\right)_{3}\right.$ is used as an example) and FTL thicknesses, predicted by Equation (5) and computed through TMM simulations, yielding maximum in MAPC are shown in Figure SI-14. Yet, further experimental verification of Equation (5) is still required for perovskites other than MAPI as the verification is only done for MAPI in this study.

\section{Conclusions}

We provided an optical design guideline for the thickness optimization of perovskite solar cells by systematically investigating the contributions of layers to the antireflection and light trapping performance. We identified an optimum $n_{F T L}$ range (i.e. $1.8<n_{F T L}<2.8$ ) providing superior ARC efficiency for MAPI. Additionally, we demonstrated that the interferences appearing at long wavelengths can be engineered to trap the light within the MAPI layer by controlling thicknesses of FTL, MAPI and RTL or those of MAPI and RTL if $n_{F T L}$ is larger or smaller than 2.1. We provided sets of equations to determine the optimum thicknesses of FTL, MAPI, and RTL of a MAPI solar cell to achieve the maxima in MAPC within an error less than $1 \%$ for given $n_{F T L}$ and $n_{R T L}$ and approximate thickness of MAPI. Additionally, we showed that the trends in MAPC with MAPI layer thicknesses are independent of the commonly used TCO materials. We generalized the guideline, experimentally-validated for MAPI, to commonly-used perovskites such as FAPI, MAPBr and $\mathrm{Cs}_{0.17} \mathrm{FA}_{0.83} \mathrm{~Pb}\left(\mathrm{Br}_{0.17} \mathrm{I}_{0.83}\right)_{3}$. We anticipate that the methodology to develop an optical design guideline can be applied to other direct band gap materials such as Cadmium Telluride (CdTe), Copper Indium Gallium Sulfide (CIGS), and Copper Zinc Tin Sulfide (CZTS) in superstrate configuration.

\section{Experimental and Computational Details}

Transfer matrix method is employed to compute reflection and absorption of layers. Finite difference time domain (FDTD) simulations are used in roughness calculations. FDTD 
simulations are performed with LUMERICAL ${ }^{\mathrm{TM}}$. Roughness is modelled as random Gaussian and defined at ITO-FTL, FTL-MAPI and MAPI-RTL interfaces. As the interference can be neglected within the relatively thick glass layer, which is therefore treated as incoherent. Optical coefficients ( $\mathrm{n}$ and $\mathrm{k}$ ) of glass, perovskite, TLs and ITO used in our calculations are taken from literature. ${ }^{[20,35,36]}$ Refractive index spectra of $\mathrm{MgF}_{2}$ and materials used in experimental section (MAPI, ITO, $\mathrm{NiO}_{\mathrm{x}}$ and $\mathrm{C}_{60}$ ) are obtained with Spectroscopic ellipsometry measurements (SOPRA GES-5E) with a spectral range from 1.23 to $5 \mathrm{eV}$ on c-Si at $70^{\circ}$ incidence angle and on glass at $57^{\circ}$ incidence angle. Cross-sectional SEM (Scanning Electron microscopy) images were obtained using FEI, Model Quanta 400 F. Reflection measurement with a spectral range of 300 to $850 \mathrm{~nm}$ was carried out using BENTHAM PVE300.

Photolithographically patterned ITO coated glass substrates were purchased from Naranjo Substrates. $\mathrm{NiO}_{x}$ sputtering target was purchased from Kurt J. Lesker. $\mathrm{PbI}_{2}$ and $\mathrm{CH}_{3} \mathrm{NH}_{3} \mathrm{I}$ (MAI) were purchased from Tokyo Chemical Industry CO. (TCI) and Lumtec, respectively. Fullerene ( $\left.\mathrm{C}_{60}\right)$ and 2,9-Dimethyl-4,7-diphenyl-1,10-phenanthroline (BCP) were purchased from sigma Aldrich.

Device fabrication: ITO coated substrates were cleaned by sonication in detergent, Acetone, Isopropyl alcohol and Deionized water for 10 minutes. The substrates were further treated by UV-ozone plasma cleaner for 10 minutes before transferring to a vacuum chamber with a base pressure of $6 \times 10^{-7}$ Torr. $\mathrm{NiO}_{\mathrm{x}}$ target was sputtered at RF power of 150 Watt and Ar-partial pressure of $6 \times 10^{-3}$ Torr to deposit $33 \mathrm{~nm}$ of compact $\mathrm{NiO}_{\mathrm{x}}$ film as HTL. Later, the $\mathrm{NiO}_{\mathrm{x}}$ coated substrates were transferred to a vacuum deposition chamber which was evacuated to $2 \times 10^{-6}$ Torr. $\mathrm{CH}_{3} \mathrm{NH}_{3} \mathrm{PbI}_{3}$ was formed by co-evaporating $\mathrm{PbI}_{2}$ and $\mathrm{CH}_{3} \mathrm{NH}_{3} \mathrm{I}$ explained in study of Perez-del-Rey et al. ${ }^{[34]}$ Briefly, $\mathrm{CH}_{3} \mathrm{NH}_{3} \mathrm{I}$ was evaporated with a temperature of approximately $70{ }^{\circ} \mathrm{C}$ and $\mathrm{PbI}_{2}$ at $250^{\circ} \mathrm{C}$. The thickness of the MAPI was monitored by two quartz crystal microbalance (QCM) sensors. After forming the MAPI layer (310, 370 and 460 
$\mathrm{nm}), \mathrm{C}_{60}(25 \mathrm{~nm})$ and $\mathrm{BCP}(7 \mathrm{~nm})$ were consecutively evaporated to deposit ETL. The substrates were later transferred to metal evaporation chamber at $1 \times 10^{-6}$ Torr to deposit 100 $\mathrm{nm}$ of silver as the top electrode.

\section{Supporting Information}

Supporting Information is available from the Wiley Online Library or from the author.

\section{Acknowledgments}

Financial support is acknowledged from TUBITAK contract number $360 \mathrm{M} 315$, and the Spanish Ministry of Economy and Competitiveness (MINECO) via the Unidad de Excelencia María de Maeztu MDM-2015-0538, MAT2017-88821-R, and PCIN-2017-014.

\section{References}

[1] Best Research-Cell Efficiencies Chart - NREL. https://www.nrel.gov/pv/assets/pdfs/pvefficiencies-07-17-2018.pdf, Accessed: 2018-10-11.

[2] M. A. Green, A. Ho-Baillie, H. J. Snaith, Nat. Photonics 2014, 8, 506.

[3] W. S. Yang, B.-W. Park, E. H. Jung, N. J. Jeon, Y. C. Kim, D. U. Lee, S. S. Shin, J. Seo, E. K. Kim, J. H. Noh, S. I. Seok, Science 2017, 356, 1376.

[4] C. Roldán-Carmona, P. Gratia, I. Zimmermann, G. Grancini, P. Gao, M. Graetzel, M. K. Nazeeruddin, Energy Environ. Sci. 2015, 8, 3550.

[5] O. Malinkiewicz, A. Yella, Y. H. Lee, G. M. Espallargas, M. Graetzel, M. K. Nazeeruddin, H. J. Bolink, Nat. Photonics 2013, 8, 128.

[6] D.-L. Wang, H.-J. Cui, G.-J. Hou, Z.-G. Zhu, Q.-B. Yan, G. Su, Sci. Rep. 2016, 6, 18922. [7] J. Wei, R.-P. Xu, Y.-Q. Li, C. Li, J.-D. Chen, X.-D. Zhao, Z.-Z. Xie, C.-S. Lee, W.-J. Zhang, J.-X. Tang, Adv. Energy Mater. 2017, 7, 1700492.

[8] F. J. Ramos, M. Oliva-Ramirez, M. K. Nazeeruddin, M. Grätzel, A. R. González-Elipe, S. Ahmad, J. Mater. Chem. A 2015, 3, 13291.

[9] Q. G. Du, G. Shen, S. John, AIP Adv. 2016, 6, 065002.

[10] M. T. Hörantner, W. Zhang, M. Saliba, K. Wojciechowski, H. J. Snaith, Energy Environ. Sci. 2015, 8, 2041.

[11] S. M. Kang, S. Jang, J.-K. Lee, J. Yoon, D.-E. Yoo, J.-W. Lee, M. Choi, N.-G. Park, Small 2016, 12, 2443. 
[12] M. M. Tavakoli, Q. Lin, S.-F. Leung, G. C. Lui, H. Lu, L. Li, B. Xiang, Z. Fan, Nanoscale 2016, 8, 4276.

[13] B. Shi, B. Liu, J. Luo, Y. Li, C. Zheng, X. Yao, L. Fan, J. Liang, Y. Ding, C. Wei, D. Zhang, Y. Zhao, X. Zhang, Sol. Energy Mater. Sol. Cells 2017, 168, 214.

[14] M. Long, Z. Chen, T. Zhang, Y. Xiao, X. Zeng, J. Chen, K. Yan, J. Xu, Nanoscale 2016, 8,6290 .

[15] A. E. Shalan, T. Oshikiri, H. Sawayanagi, K. Nakamura, K. Ueno, Q. Sun, H.-P. Wu, E. W.-G. Diau, H. Misawa, Nanoscale 2017, 9, 1229.

[16] T. Shen, S. Siontas, D. Pacifici, J. Phys. Chem. C 2018, 122, 23691.

[17] R. Santbergen, R. Mishima, T. Meguro, M. Hino, H. Uzu, J. Blanker, K. Yamamoto, M. Zeman, Opt. Express 2016, 24, A1288.

[18] C. O. Ramírez Quiroz, Y. Shen, M. Salvador, K. Forberich, N. Schrenker, G. D.

Spyropoulos, T. Heumüller, B. Wilkinson, T. Kirchartz, E. Spiecker, P. J. Verlinden, X.

Zhang, M. A. Green, A. Ho-Baillie, C. J. Brabec, J. Mater. Chem. A 2018, 6, 3583.

[19] Q. Lin, A. Armin, R. C. R. Nagiri, P. L. Burn, P. Meredith, Nat. Photonics 2014, 9, 106.

[20] C.-W. Chen, S.-Y. Hsiao, C.-Y. Chen, H.-W. Kang, Z.-Y. Huang, H.-W. Lin, J. Mater. Chem. A 2015, 3, 9152.

[21] J. M. Ball, S. D. Stranks, M. T. Hörantner, S. Hüttner, W. Zhang, E. J. W. Crossland, I. Ramirez, M. Riede, M. B. Johnston, R. H. Friend, H. J. Snaith, Energy Environ. Sci. 2015, 8, 602.

[22] S. Albrecht, M. Saliba, J.-P. Correa-Baena, K. Jäger, L. Korte, A. Hagfeldt, M. Grätzel, B. Rech, J. Opt. (Bristol, U. K.) 2016, 18, 064012.

[23] M. Filipic, P. Loeper, B. Niesen, S. De Wolf, J. Krc, C. Ballif, M. Topic, Opt. Express 2015, 23, 16. A263.

[24] Y. Jiang, I. Almansouri, S. Huang, T. Young, Y. Li, Y. Peng, Q. Hou, L. Spiccia, U. Bach, Y.-B. Cheng, M. A. Green, A. Ho-Baillie, J. Mater. Chem. C 2016, 4, 5679.

[25] D. T. Grant, K. R. Catchpole, K. J. Weber, T. P. White, Opt. Express 2016, 24, A1454.

[26] P. M. Kaminski, P. J. M. Isherwood, G. Womack, J. M. Walls, Energy Procedia 2016, $102,11$.

[27] L. M. Pazos-Outón, M. Szumilo, R. Lamboll, J. M. Richter, M. Crespo-Quesada, M. Abdi-Jalebi, H. J. Beeson, M. Vrućinić, M. Alsari, H. J. Snaith, B. Ehrler, R. H. Friend, F. Deschler, Science 2016, 351, 1430.

[28] J. M. Richter, M. Abdi-Jalebi, A. Sadhanala, M. Tabachnyk, J. P. H. Rivett, L. M. PazosOutón, K. C. Gödel, M. Price, F. Deschler, R. H. Friend, Nat. Commun. 2016, 7, 13941. 
[29] J. You, Z. Hong, Y. (Michael) Yang, Q. Chen, M. Cai, T.-B. Song, C.-C. Chen, S. Lu, Y. Liu, H. Zhou, Y. Yang, ACS Nano 2014, 8, 1674.

[30] W. Ke, G. Fang, J. Wang, P. Qin, H. Tao, H. Lei, Q. Liu, X. Dai, X. Zhao, ACS Appl. Mater. Interfaces 2014, 6, 15959.

[31] J.-Y. Jeng, K.-C. Chen, T.-Y. Chiang, P.-Y. Lin, T.-D. Tsai, Y.-C. Chang, T.-F. Guo, P. Chen, T.-C. Wen, Y.-J. Hsu, Adv. Mater. 2014, 26, 4107.

[32] T.-L. Chiu, H. Mandal, M. Zhang, S.-P. Yang, Y.-T. Chuang, Int. J. Photoenergy 2013, 2013, 7.

[33] C. Momblona, L. Gil-Escrig, E. Bandiello, E. M. Hutter, M. Sessolo, K. Lederer, J. Blochwitz-Nimoth, H. J. Bolink, Energy Environ. Sci. 2016, 9, 3456.

[34] D. Pérez-del-Rey, P. P. Boix, M. Sessolo, A. Hadipour, H. J. Bolink, J. Phys. Chem. Lett. 2018, 9, 1041.

[35] I. H. Malitson, J. Opt. Soc. Am. 1965, 55, 1205.

[36] T. Siefke, S. Kroker, K. Pfeiffer, O. Puffky, K. Dietrich, D. Franta, I. Ohlídal, A. Szeghalmi, E.-B. Kley, A. Tünnermann, Adv. Opt. Mater. 2016, 4, 1780. 


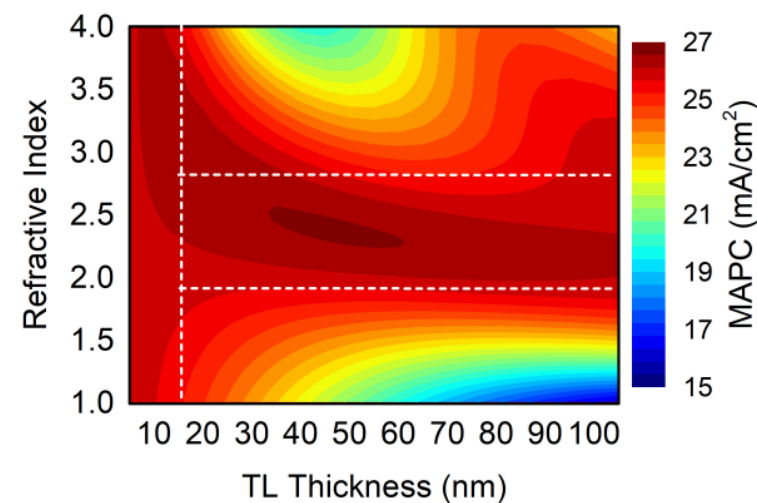

(a)

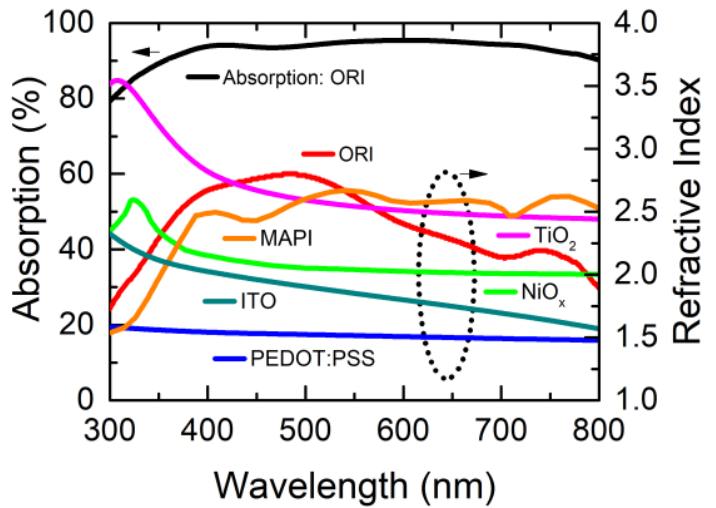

(b)

Figure 1. MAPC of semi-infinite MAPI as a function of the thickness and refractive index of a hypothetical FTL upon a $70 \mathrm{~nm}$-thick ITO (a). Dashed lines separate three regions with distinct behaviors. An optimum refractive index (ORI) spectrum of a 30 nm-thick FTL on semi-infinite MAPI, refractive index spectra of PEDOT:PSS, $\mathrm{NiO}_{\mathrm{x}}$, $\mathrm{TiO}_{2}$, MAPI and ITO, and absorption spectrum of a semi-infinite MAPI with a $30 \mathrm{~nm}$ thick FTL with the ORI (b). 

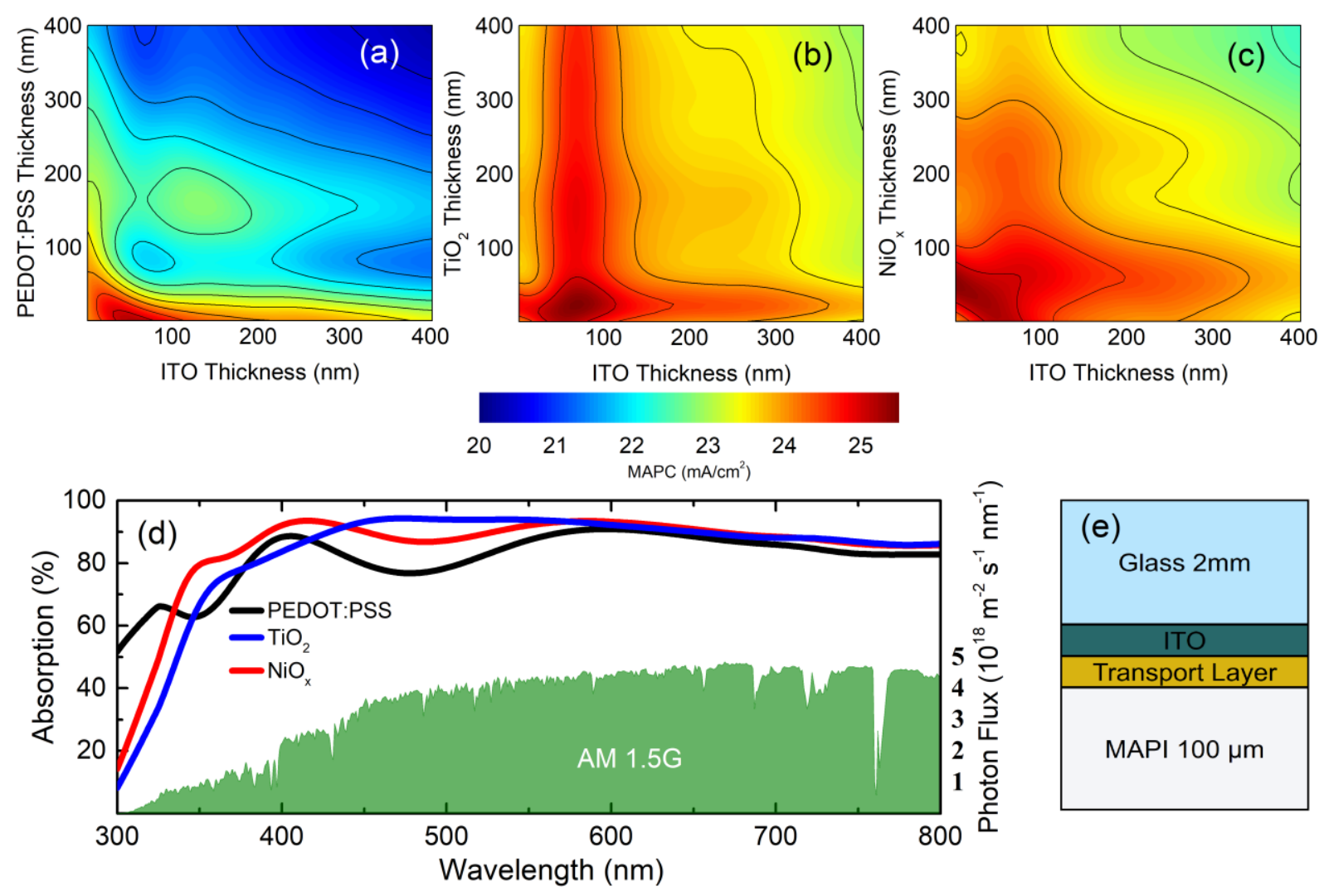

(e) Glass 2mm

Figure 2. MAPC of semi-infinite MAPI at various thicknesses of ITO and (a) PEDOT:PSS, (b) $\mathrm{TiO}_{2}$, (c) $\mathrm{NiO}_{\mathrm{x}}$. Absorption spectra of semi-infinite MAPI when a 30 $\mathrm{nm}$ TL and $210 \mathrm{~nm}$ ITO are used (d) together with the AM 1.5G spectrum for the photon flux (green shaded area). The simulated structure (e). 


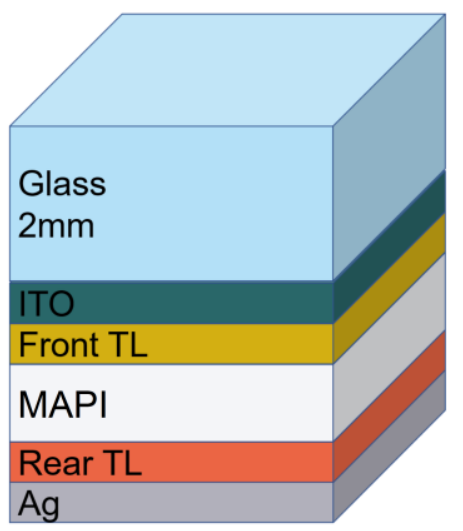

(a)

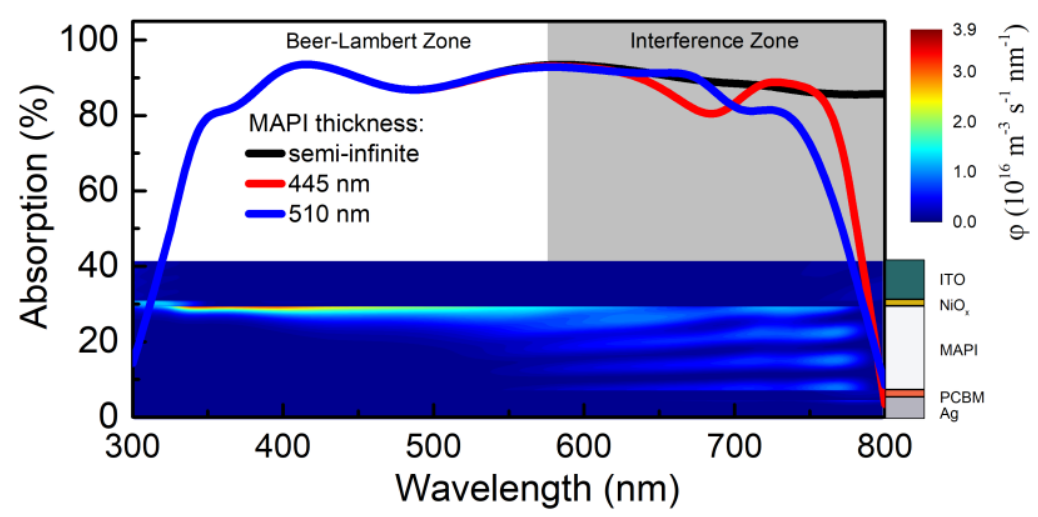

(b)

Figure 3 A schematic of the simulated structure (a). Absorption spectra of MAPI at thicknesses of semi-infinite, $445 \mathrm{~nm}$ and $510 \mathrm{~nm}$ for $\mathrm{NiO}_{\mathrm{x}}, \mathrm{PCBM}$ and $\mathrm{Ag}$ thicknesses of $30 \mathrm{~nm}, 50 \mathrm{~nm}, 100 \mathrm{~nm}$, respectively. Inset of (b): The spectral rate of photon absorption profile within the depth of $445 \mathrm{~nm}$ MAPI. 


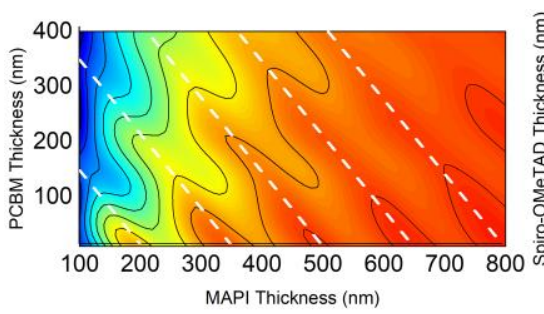

a

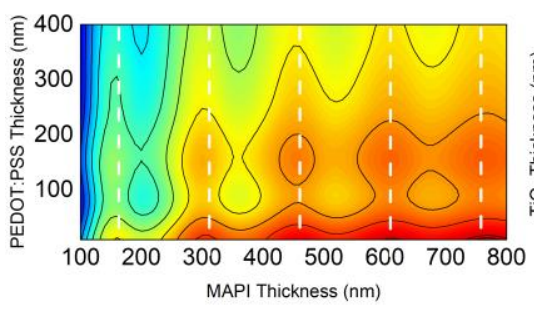

b

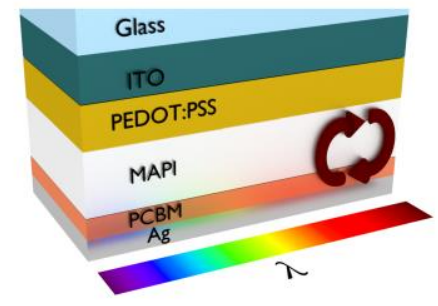

C

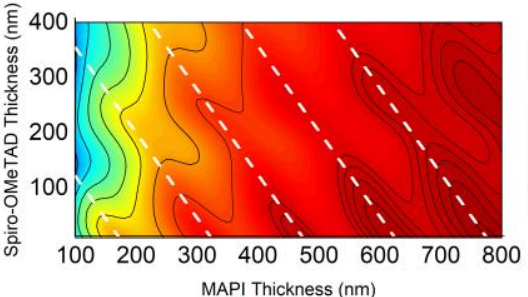

d

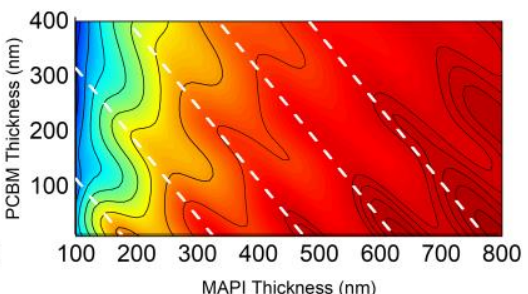

g

$\begin{array}{llllllllllll}13 & 14 & 15 & 16 & 17 & 18 & 19 & 20 & 21 & 22 & 23 & 24\end{array}$ $\operatorname{MAPC}\left(\mathrm{mA} / \mathrm{cm}^{2}\right)$

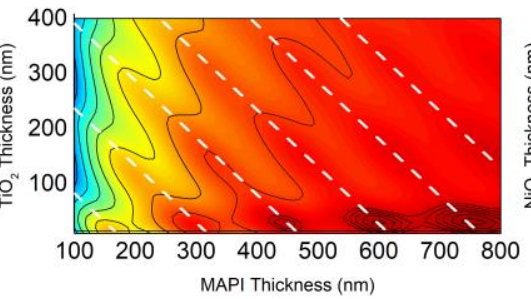

e

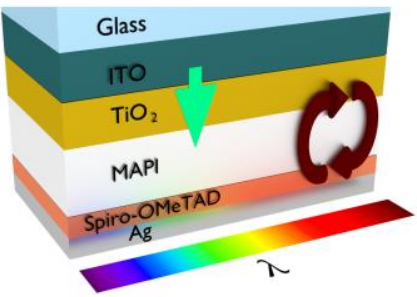

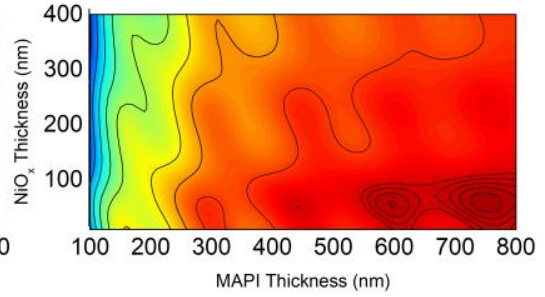

$\mathrm{h}$

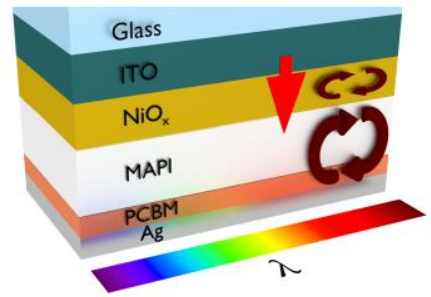

f

Figure 4. MAPCs as a function of MAPI and RTL thicknesses (a, $d$ and g), and MAPI and FTL thicknesses (b, e and f) for PEDOT:PSS, $\mathrm{TiO}_{2}$ and $\mathrm{NiO}_{\mathrm{x}}$ FTLs, respectively. Light trapping (circular arrows) and ARC (vertical arrows) mechanisms are presented at (c), (f) and (i). 

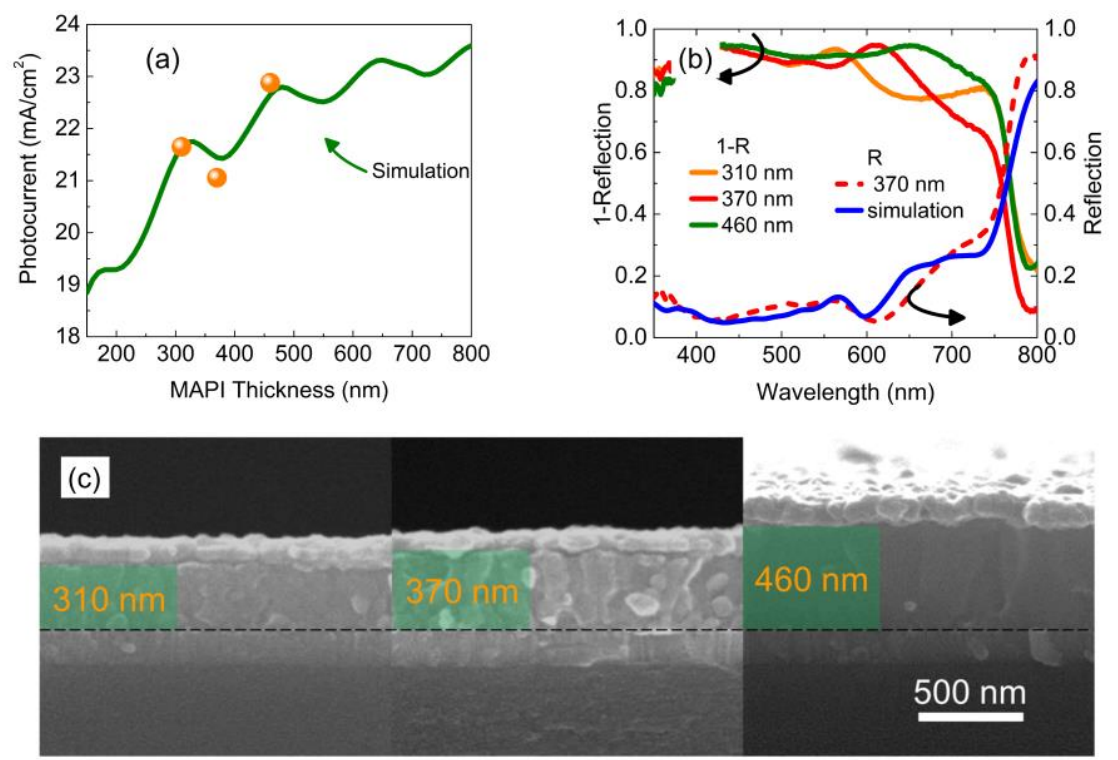

Figure 5. (a) Total available photocurrent (in wavelengths between 350 and 800 nm) calculated using Equation 1 where $A$ is replaced by 1-R as a function of MAPI thicknesses for a MAPI solar cell with $115 \mathrm{~nm}$ ITO, $33 \mathrm{~nm} \mathrm{NiO}$, $25 \mathrm{~nm} \mathrm{C}_{60}, 7 \mathrm{~nm}$ BCP and $100 \mathrm{~nm} \mathrm{Ag.} \mathrm{Orange} \mathrm{circles,} \mathrm{extracted} \mathrm{from} \mathrm{1-reflection} \mathrm{measurements,} \mathrm{are} \mathrm{the} \mathrm{total}$ available photocurrent of fabricated solar cells with MAPI thicknesses of 310, 370 and

$460 \mathrm{~nm}$. Inset: cross-section SEM images of fabricated solar cells. (b) Measured 1Reflection spectra for MAPI solar cells with thicknesses of 310,370 and $460 \mathrm{~nm}$, and measured and simulated reflection spectrum for the MAPI solar cell with a thickness of $370 \mathrm{~nm}$. 


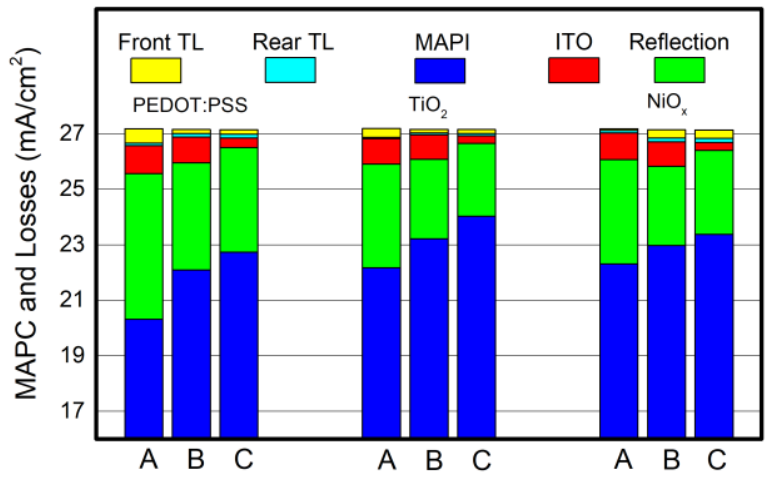

a

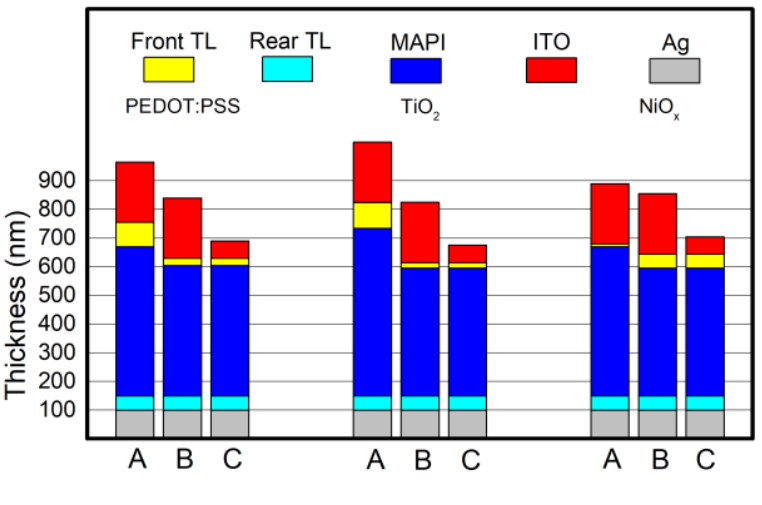

b

Figure 6. MAPC, and reflection and parasitic absorption losses are given in $\mathbf{m A} / \mathrm{cm}^{2}$ units for MAPI solar cells utilizing PEDOT:PSS, $\mathrm{NiO}_{\mathrm{x}}$ and $\mathrm{TiO}_{2}$ as FTL (a) and corresponding layer thicknesses are given in (b). A denotes the non-optimum MAPI, FTL and ITO thicknesses, B denotes the optimum MAPI and FTL thicknesses but nonoptimum ITO thickness and C denotes the optimum MAPI, FTL and ITO thicknesses. 
Table 1. Summary of equations that needs to be used when calculating the $t_{F T L}, t_{M A P I}$ and $t_{R T L}$ for various $n_{F T L}$ ranges. The values of refractive indices should be taken for $\lambda=450$ $\mathrm{nm}$ in Equation 4 and $\lambda=770 \mathrm{~nm}$ in Equation 2 and 3.

\begin{tabular}{c|c|c}
$n_{F T L}$ range & $t_{F T L}$ & $t_{M A P I} \& t_{R T L}$ \\
\hline$<1.8$ & $\sim 0 \mathrm{~nm}$ & Equation 2 \\
$1.8-2.1$ & Equation 4 & Equation 2 \\
$2.1-2.8$ & Equation 4 & Equation 3 \\
$2.8<$ & $\sim 0 \mathrm{~nm}$ & Equation 3
\end{tabular}


The optical mechanisms leading to highly efficient planar perovskite solar cells commonly lack profound insight. In this paper, a comprehensive guideline for thickness optimization of the front and rear transport layers, perovskite, and transparent conductive oxides to maximize the photocurrent of perovskite solar cells by means of enhanced antireflection and light trapping is introduced.

Keywords: optical modelling, thickness optimization, light trapping, anti-reflection, perovskite solar cells, planar solar cells, optimization guideline

Mehmet Koç, Wiria Soltanpoor,Gence Bektaş, Henk J. Bolink, Selçuk Yerci*

\section{Guideline for Optical Optimization of Planar Perovskite Solar Cells}

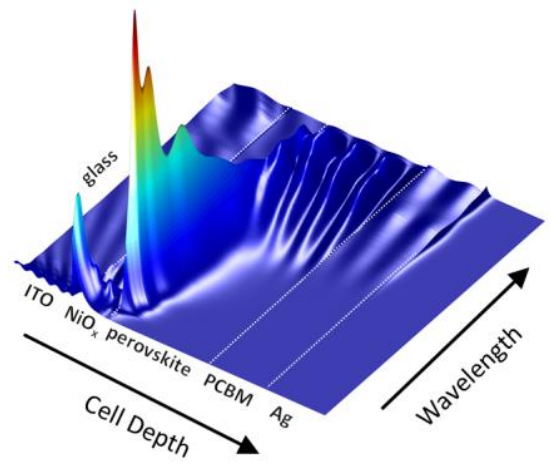


Copyright WILEY-VCH Verlag GmbH \& Co. KGaA, 69469 Weinheim, Germany, 2018.

\section{Supporting Information}

Supporting Information: Guideline for Optical Optimization of Planar Perovskite Solar Cells Mehmet Koç ${ }^{1,2,3}$, Wiria Soltanpoor ${ }^{1,2,5}$, Gence Bektaş ${ }^{1,2}$, Henk J. Bolink ${ }^{5}$, Selçuk Yerci ${ }^{1,2,4, *}$

${ }^{1}$ The Center for Solar Energy Research and Applications (GÜNAM), Ankara, Turkey

${ }^{2}$ Micro and Nanotechnology Department, Middle East Technical University, Ankara, Turkey

${ }^{3}$ Department of Electrical and Electronics Engineering, Ankara Ylldırım Beyazıt University, Ankara, Turkey

${ }^{4}$ Department of Electrical and Electronics Engineering, Middle East Technical University, Ankara, Turkey

${ }^{5}$ Instituto de Ciencia Molecular, Universidad de Valencia, C/Cat. J. Beltran 2, 46980 Paterna, Spain

*syerci@metu.edu.tr 


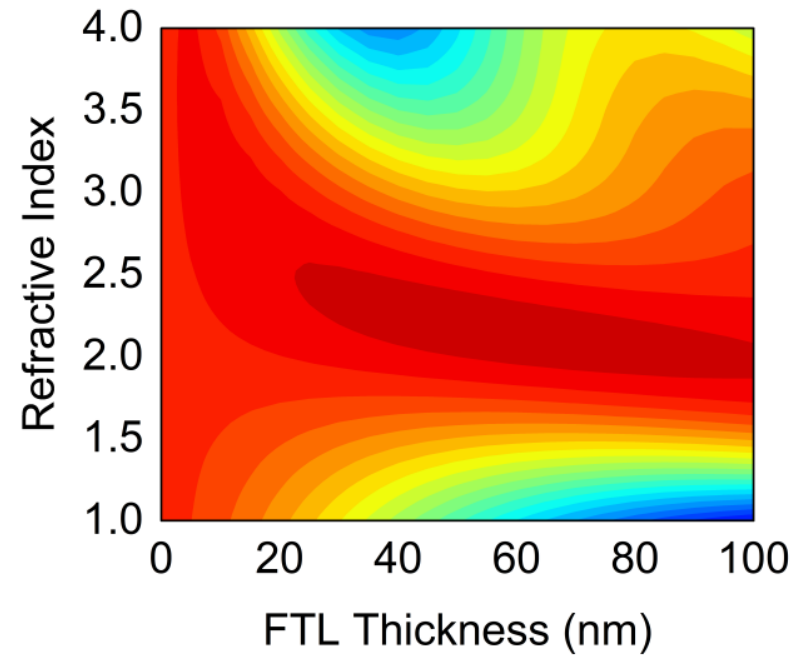

(a)

$\begin{array}{lllllllllllll}15 & 16 & 17 & 18 & 19 & 20 & 21 & 22 & 23 & 24 & 25 & 26 & 27\end{array}$

MAPC $\left(\mathrm{mA} / \mathrm{cm}^{2}\right)$

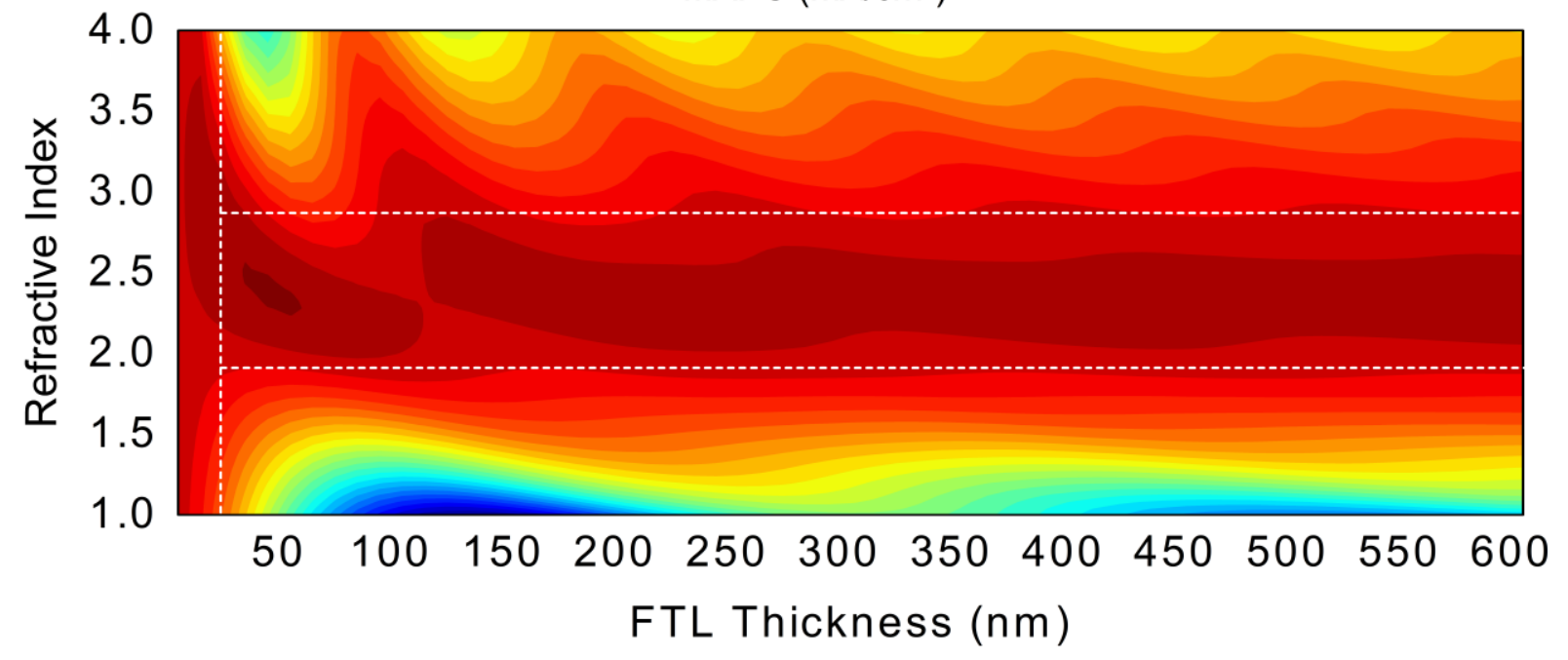

(c)

Figure SI-1. MAPC for a semi-infinite MAPI as a function of FTL thickness and refractive index for ITO thicknesses of (a) $150 \mathrm{~nm}$, (b) $210 \mathrm{~nm}$, and (c) $70 \mathrm{~nm}$. The white solid line in (b) indicates the optimum FTL thickness for FTL refractive index calculated with Equation (4). White dashed lines in (c) separate three regions with distinct behaviors. 

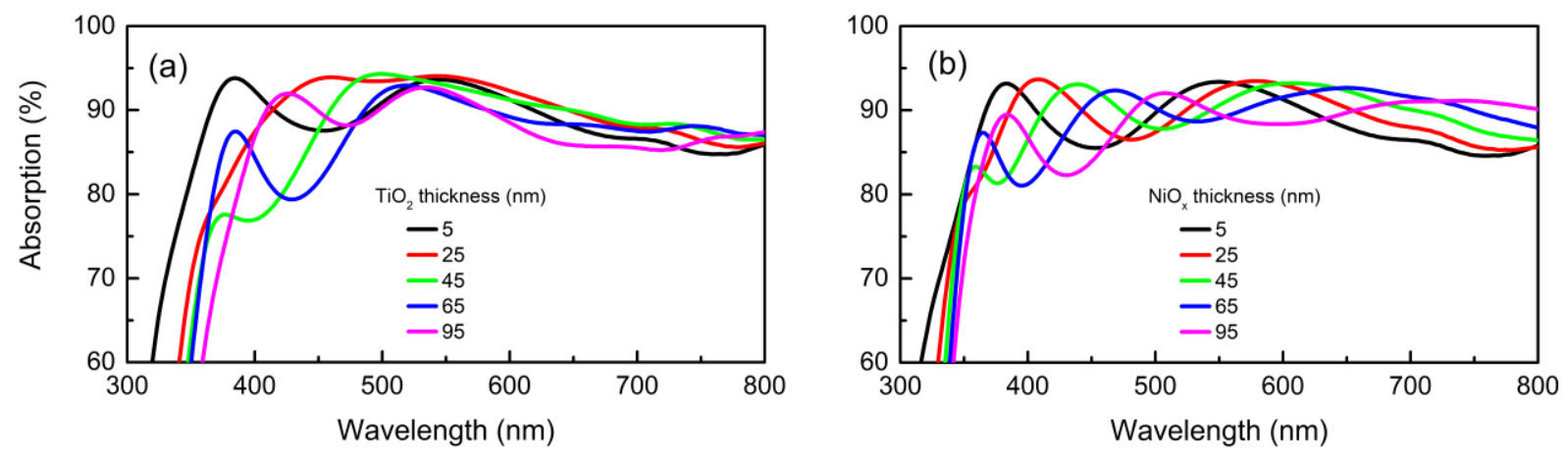

Figure SI-2. Absorption spectra of semi-infinite MAPI for various $\mathrm{TiO}_{2}$ and $\mathrm{NiO}_{x}$ thicknesses.

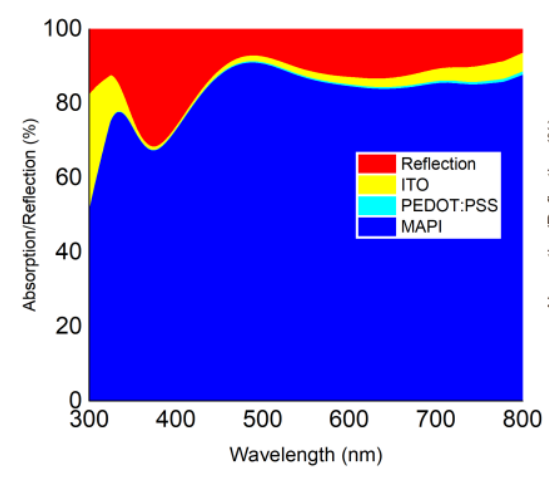

(a)

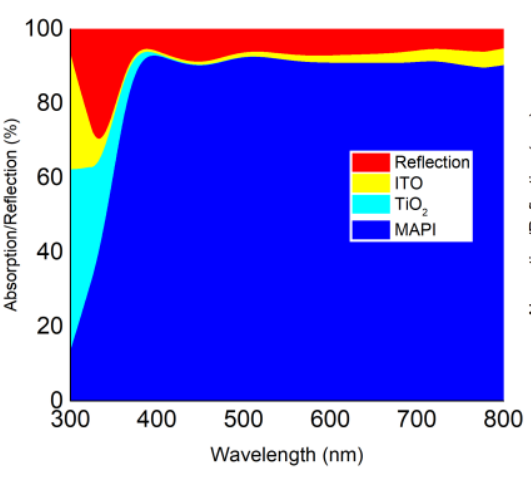

(b)

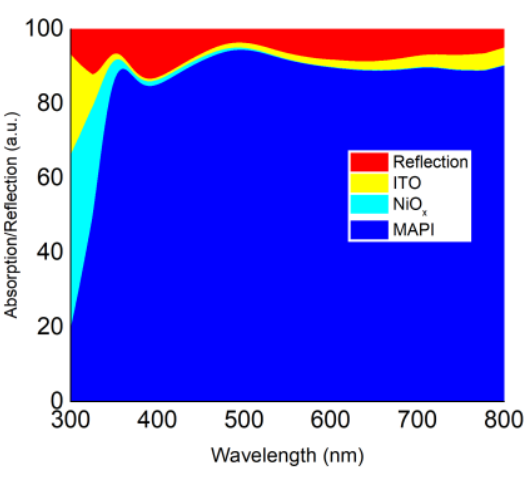

(c)

Figure SI-3. Optical losses (i.e. reflection and parasitic absorption) and absorption spectra of semi-infinite MAPI with (a) $30 \mathrm{~nm}$-thick PEDOT:PSS, (b) $30 \mathrm{~nm}$-thick $\mathrm{TiO}_{2}$ and (c) 30 nm-thick NiOx.

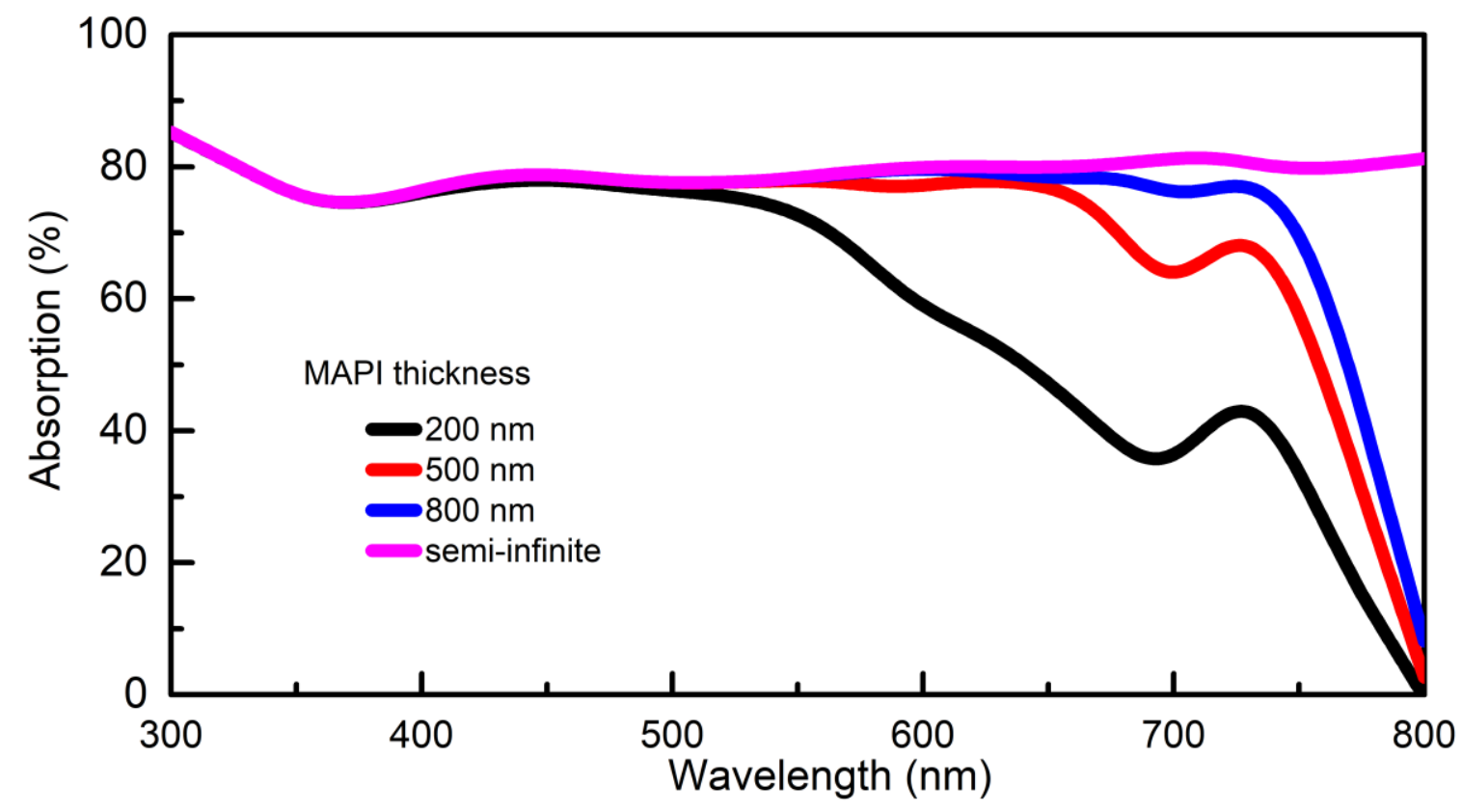

Figure SI-4. Absorption spectra of $200 \mathrm{~nm}-, 500 \mathrm{~nm}$ - and $800 \mathrm{~nm}$-thick MAPI along with semi-infinite $100 \mu \mathrm{m}$ MAPI for a NiO thickness of $30 \mathrm{~nm}$. The thickness of PCBM is $50 \mathrm{~nm}$ in case of finite MAPI layers. 


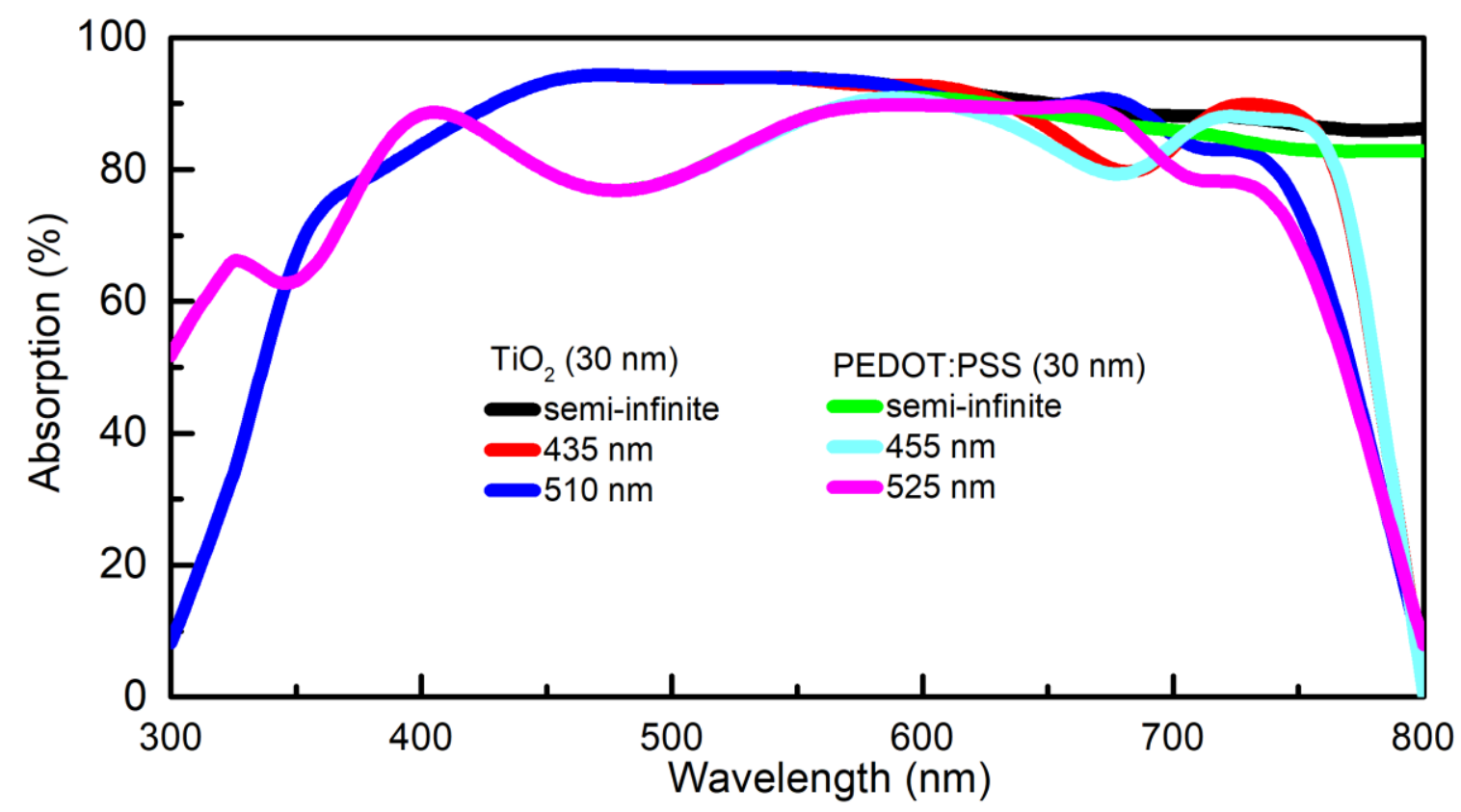

Figure SI-5. Absorption spectra of MAPI for MAPI thickness leading to local maxima and minima, and for semi-infinite MAPI. The thicknesses of $\mathrm{TiO}_{2}$ and PEDOT:PSS are $30 \mathrm{~nm}$. The thickness of PCBM is $50 \mathrm{~nm}$ in case of finite MAPI layers.

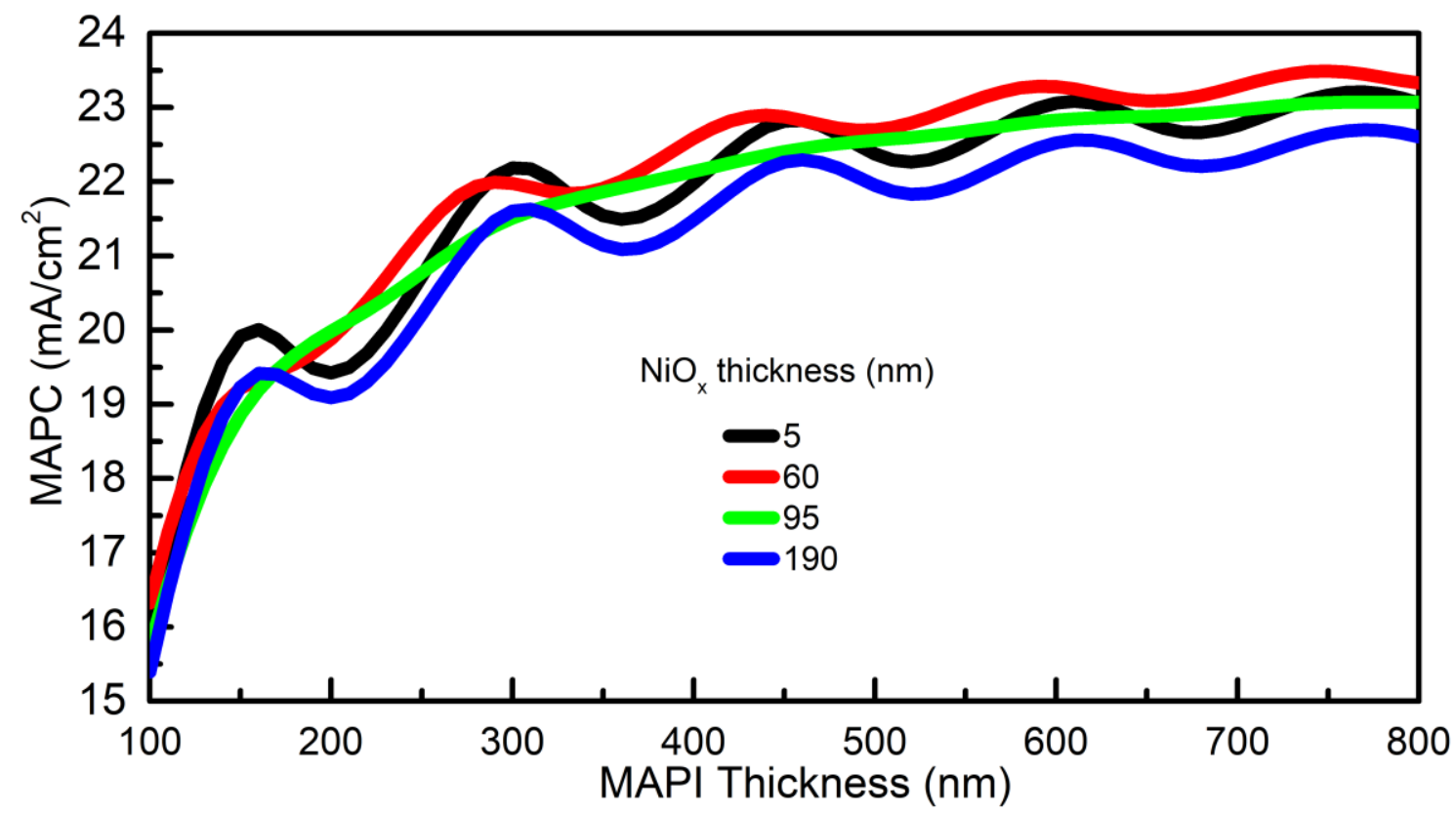

Figure SI-6. MAPC as a function of MAPI thickness for various thicknesses of $\mathrm{NiO}_{\mathrm{x}}$ as front TL. 


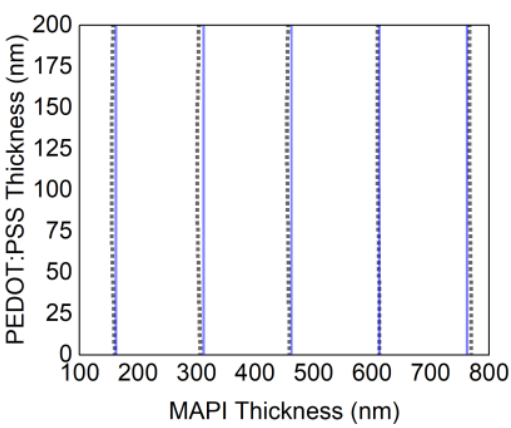

a

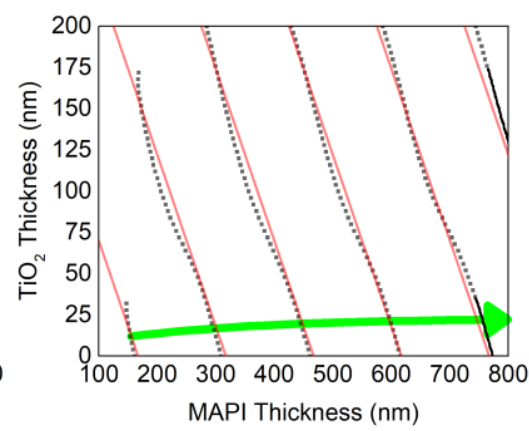

b

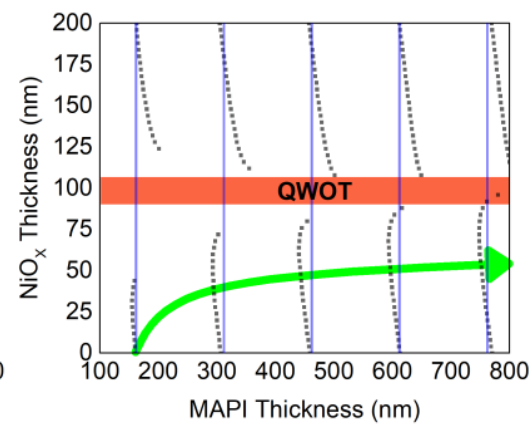

C

Figure SI-7. Maximal trends in MAPC for various interference orders when (a) PEDOT:PSS, (b) $\mathrm{TiO}_{2}$ and (c) $\mathrm{NiO}_{x}$ is used as FTL (black squares). Maximal trends predicted using Equation (2) and (3) are shown by solid blue and red lines. Green arrows in (b) and (c) indicated the optimum $\mathrm{TiO}_{2}$ and $\mathrm{NiO}_{x}$ thicknesses in terms of $\mathrm{ARC}$ efficiency. Orange band in (c) indicates $\mathrm{NiO}_{x}$ thickness range providing QWOT condition hindering occurrence of interference in MAPI solar cell.
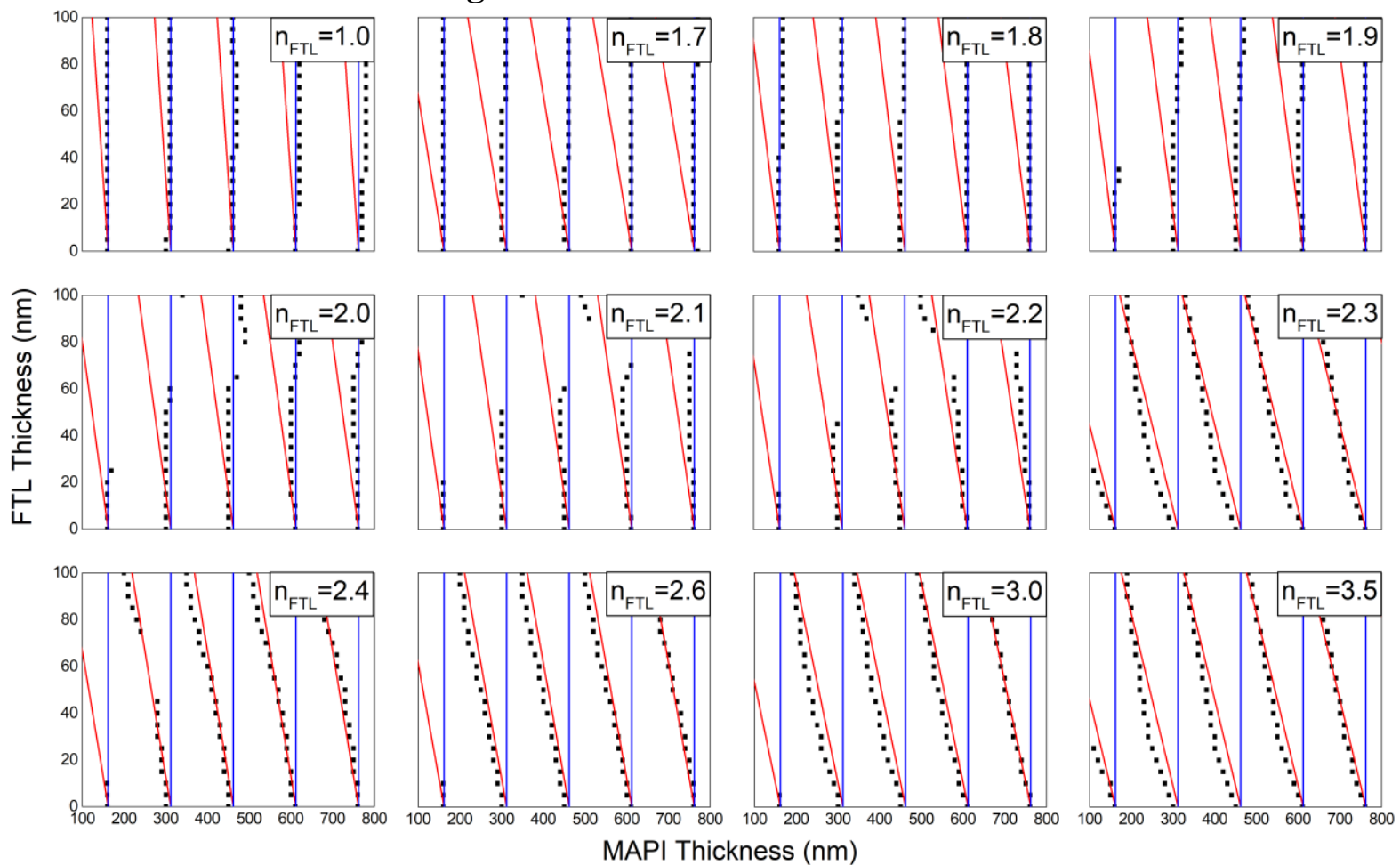

Figure SI-8. Computed maximal trends (black squares) in MAPC for various interference orders for hypothetical FTLs with refractive indices between 1.0 and 3.5 and with no extinction coefficient. Maximal trends predicted using Equation (2) and (3) are shown by solid blue and red lines. 

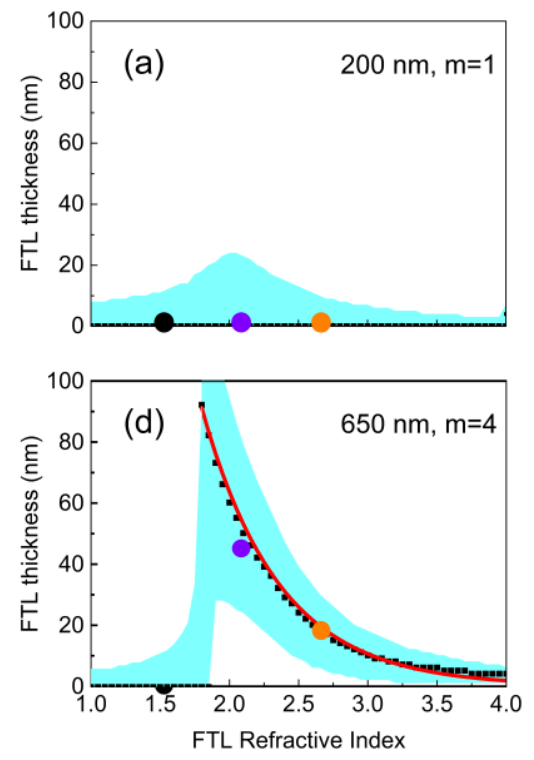
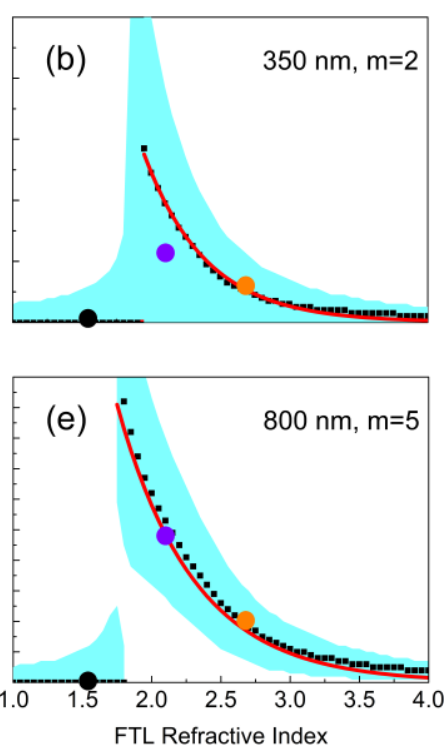
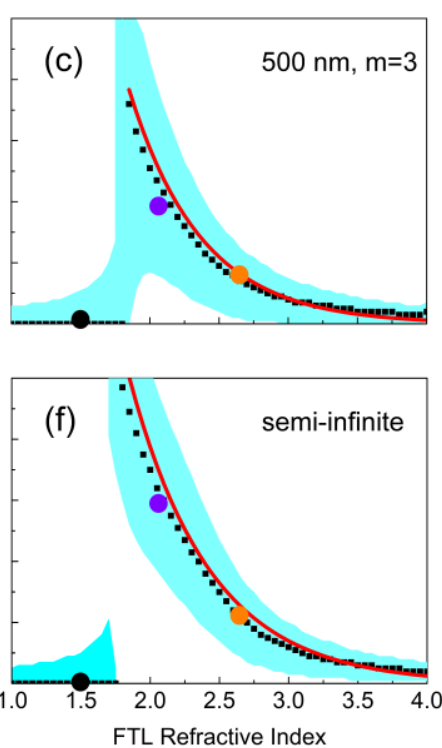

Figure SI-9. The optimum FTL thickness (black squares) with respect to FTL refractive index for interference orders of (a) 1, (b) 2, (c) 3, (d) 4, (e) 5 and for semi-infinite MAPI.

The RTL thickness is set to zero. Black, purple and orange dots indicate the optimum

FTL thickness of PEDOT:PSS, $\mathrm{NiO}_{\mathrm{x}}$ and $\mathrm{TiO}_{2}$ obtained using their experimental refractive index and extinction coefficients, respectively. The solid red line shows optimum thickness prediction of Equation 4.

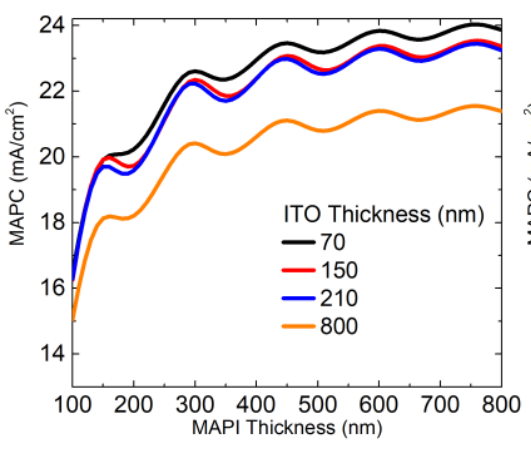

(a)

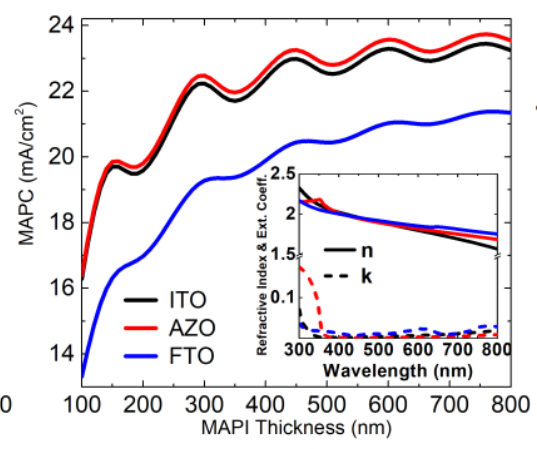

(b)

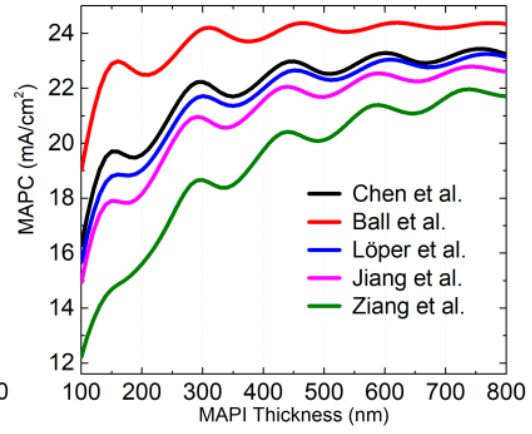

(c)

Figure SI-10. Variation of MAPC with MAPI thickness for (a) various ITO thicknesses, (b) different TCO materials with $210 \mathrm{~nm}$ thickness, and (c) various MAPIs. ${ }^{[1]}$ Inset of (b): refractive index and extinction coefficient spectra of the TCO materials. ${ }^{[2,4]} \mathrm{NiO}_{\mathrm{x}}$ and PCBM thicknesses are taken as $30 \mathrm{~nm}$ and $50 \mathrm{~nm}$, respectively. MAPC decreases with the thickness (a) and the extinction coefficient (inset of b) of TCO due to enhanced parasitic absorption. The extensive parasitic loss in FTO smooths out MAPC variation with MAPI thickness. ${ }^{[3,5]}$ The variations in optimum MAPI thicknesses are within a range of $10 \mathrm{~nm}$ for various MAPIs. 


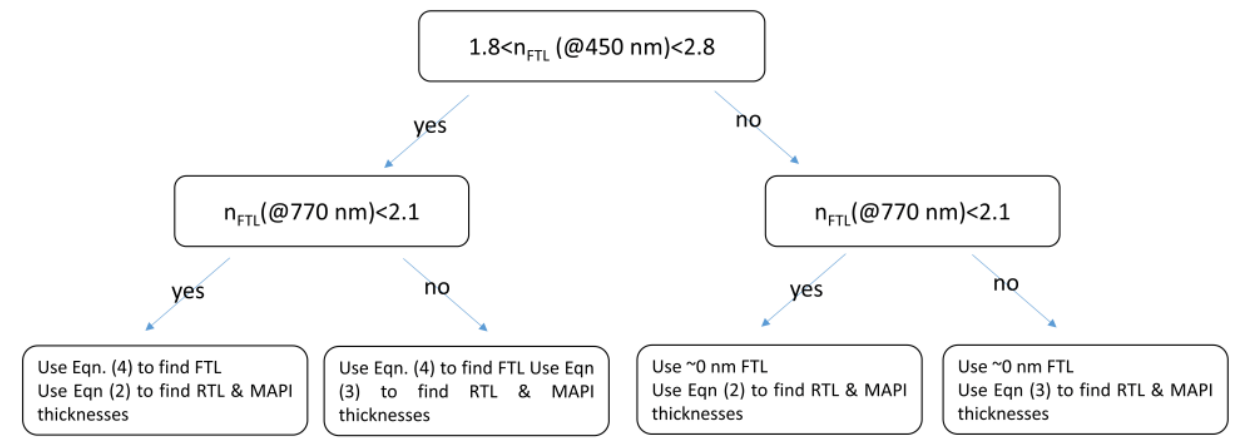

Figure SI-11. Diagram showing the thickness optimization guideline of FTL, MAPI and RTL to achieve maximum MAPC.

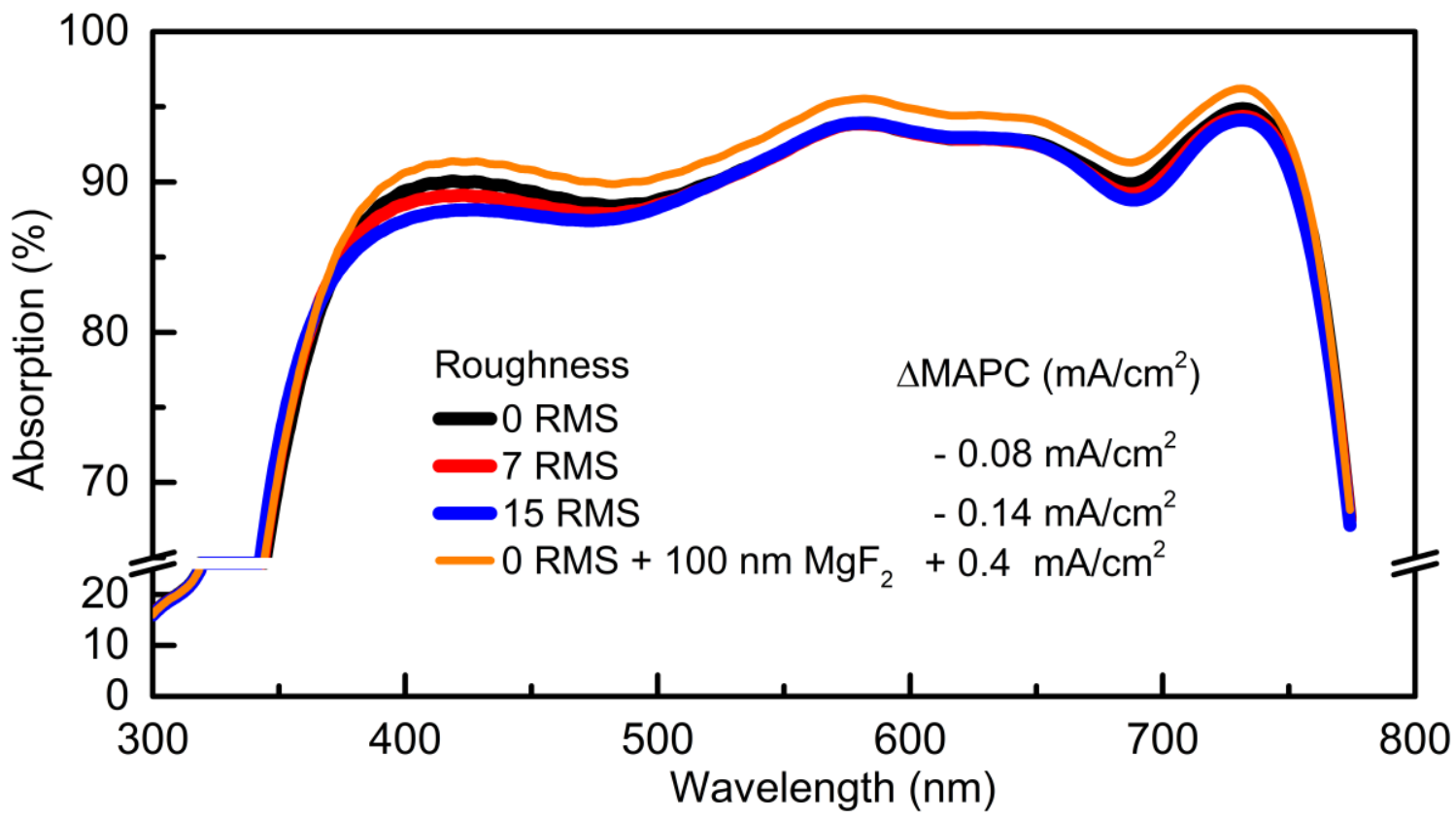

Figure SI-12. Absorption spectra of a MAPI solar cell with $50 \mathrm{~nm}$ NiOx, $445 \mathrm{~nm}$ MAPI and $50 \mathrm{~nm}$ RTL, and with no roughness (black), $7 \mathrm{~nm}$ RMS roughness (red) and $15 \mathrm{~nm}$ RMS roughness (blue). Roughness slightly reduces absorption in MAPI primarily in the UV part of the spectrum where scattering is more significant, and therefore leads to an optical path length increase and parasitic absorption losses in FTL with relatively large extinction coefficients such as $\mathrm{NiO}_{x}$ and $\mathrm{TiO}_{2}$. Absorption spectrum of a MAPI solar cells with the same thicknesses of layers having no roughness but a $100 \mathrm{~nm}$-thick $\mathrm{MgF}_{2}$ ARC on glass (orange line). 


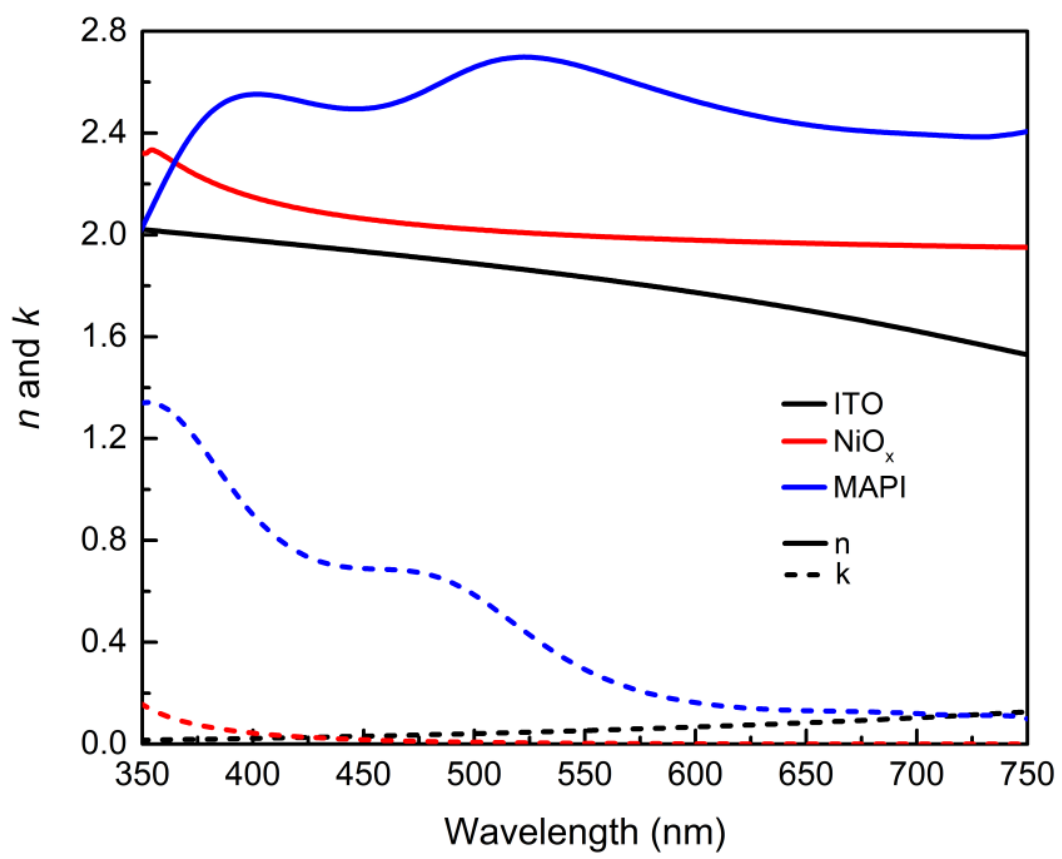

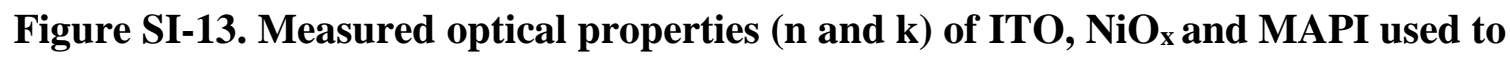
fabricate device.

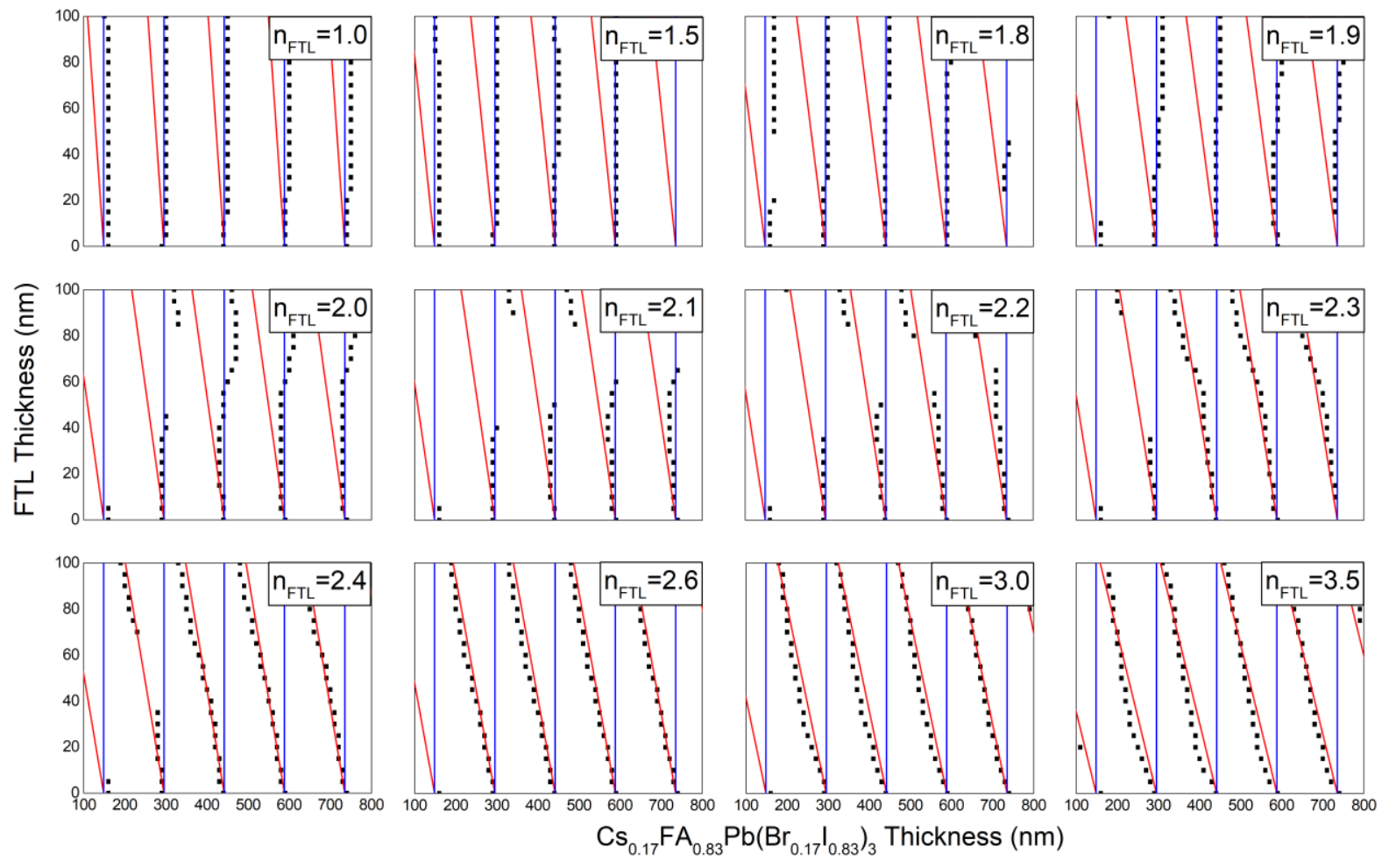

Figure SI-14. Computed maximal trends (black squares) for $\mathrm{Cs}_{0.17} \mathrm{FA} \mathrm{A}_{0.83} \mathrm{~Pb}\left(\mathrm{Br}_{0.17} \mathrm{I}_{0.83}\right)_{3}$ in MAPC for various interference orders for hypothetical FTLs with refractive indices between 1.0 and 3.5 and with no extinction coefficient. Maximal trends predicted using Equation (5) are shown by solid blue and red lines. 
Table SI-1. TCO, FTL, RTL material information, refractive indices of FTL (both at $450 \mathrm{~nm}$ and $770 \mathrm{~nm}$ ), MAPI (at $770 \mathrm{~nm})$ and RTL (at $770 \mathrm{~nm}$ ), and estimated interference order and cut-off FTL refractive index acquired from publications of Ball et al., ${ }^{[3]}$ Lin et al. ${ }^{[6]}$ and Chen et al. ${ }^{[2]}$

\begin{tabular}{|c|c|c|c|c|c|}
\hline & Ball(1) & $\operatorname{Ball}(2)$ & Lin & Chen(1) & Chen(2) \\
\hline TCO & FTO & FTO & ITO & ITO & ITO \\
\hline FTL & $\mathrm{TiO}_{2}$ & $\mathrm{TiO}_{2}$ & PEDOT:PSS/PCDTBT & $\mathrm{ZnO}$ & PEDOT:PSS \\
\hline RTL & Spiro. & Spiro. & PCBM & Spiro. & PCBM \\
\hline$n_{F T L} @ 450 \mathrm{~nm}$ & 2.20 & 2.20 & 1.63 & 2.04 & 1.53 \\
\hline$n_{F T L} @ 770 \mathrm{~nm}$ & 2.07 & 2.07 & 1.58 & 1.93 & 1.48 \\
\hline$n_{M A P I} @ 770 \mathrm{~nm}$ & 2.59 & 2.59 & 2.82 & 2.61 & 2.61 \\
\hline$m$ & 4 & 5 & 2 & 4 & 3 \\
\hline$n_{\text {cut-off }}$ & 1.80 & 1.80 & 1.95 & 1.80 & 1.85 \\
\hline
\end{tabular}

Table SI-2. Optimum FTL, MAPI and RTL thicknesses calculated via optical simulations by Ball et al., Lin et al. and Chen et al., and using Equation 2, 3 and 4 following the guideline given in this article.

\begin{tabular}{c|c|c|c} 
& FTL & MAPI & RTL (fixed) \\
\hline Ball (1) & 41 & 470 & 253 \\
Our guideline & 34 & 478 & 253 \\
Ball (2) & 41 & 630 & 253 \\
Our guideline & 39 & 628 & 253 \\
Lin & 15 & 350 & 10 \\
Our guideline & 0 & 343 & 10 \\
Chen (1) & 40 (fixed) & 460 & 300 \\
Our guideline & 44 & 451 & 300 \\
Chen (2) & 40 (fixed) & 435 & 100 \\
Our guideline & 0 & 424 & 100
\end{tabular}


Table SI-3. Generalized optimum thicknesses of $\mathrm{ABX}_{3}(\mathrm{~B}=\mathrm{Pb})$, RTL and FTL prediction

\begin{tabular}{|c|c|c|c|c|c|c|}
\hline & for & nula par & amete & & & \\
\hline A & $\mathrm{X}_{3}$ & $\begin{array}{l}\lambda_{\text {abs.onset }} \\
(\mathrm{nm})\end{array}$ & $\begin{array}{l}t_{\text {offset }} \\
(\mathrm{nm})\end{array}$ & $\begin{array}{c}\lambda_{o} \\
(\mathrm{~nm})\end{array}$ & $n_{\text {threshold }}$ & Ref. \\
\hline MA & I & 790 & 50 & 775 & 2.1 & [2] \\
\hline MA & I & 795 & 50 & 770 & 2.1 & [3] \\
\hline MA & I & 780 & 50 & 750 & 2.1 & [6] \\
\hline MA & I & 790 & 50 & 770 & 2.1 & [7] \\
\hline MA & I & 779 & 50 & 750 & 2.1 & [8] \\
\hline MA & I & 776 & 50 & 750 & 2.1 & [9] \\
\hline MA & I & 795 & 50 & 770 & 2.1 & [10] \\
\hline MA & I & 780 & 50 & 770 & 2.1 & [12] \\
\hline FA & I & 827 & 40 & 780 & 1.8 & [10] \\
\hline $\mathrm{Cs}_{0.15} \mathrm{FA}_{0.85}$ & $\mathrm{I}$ & 821 & 40 & 780 & 1.8 & [10] \\
\hline $\mathrm{Cs}_{0.17} \mathrm{FA}_{0.83}$ & $\mathrm{Br}_{0.17} \mathrm{I}_{0.83}$ & 761 & 40 & 750 & 2.1 & [11] \\
\hline $\mathrm{Cs}_{0.25} \mathrm{FA}_{0.75}$ & $\mathrm{Br}_{0.20} \mathbf{I}_{0.80}$ & 739 & 40 & 710 & 2.2 & [11] \\
\hline MA & $\mathrm{Br}$ & 539 & 50 & 530 & 1.8 & [10] \\
\hline FA & $\mathrm{Br}$ & 554 & 50 & 530 & 1.8 & [10] \\
\hline
\end{tabular}

Table SI-4. Accuracy comparison of generalized Equation (5) for various perovskites (i.e. $\mathrm{ABX}_{3}, \mathrm{~B}=\mathrm{Pb}$ ) for various FTL thicknesses for the interference order of $3 . \Delta \mathrm{t}_{\text {error }}$ is calculated by averaging the differences between the optimal perovskite thicknesses found using Equation (5) and calculated through TMM simulations over various FTL thicknesses. The thickness difference can be seen in Figures SI-8 for MAPI and SI-14 for

\begin{tabular}{c|c|c|c|c|c}
\multicolumn{5}{|c}{ Cs0.17FA0.83Pb(Bro.17 $\left.\mathbf{I}_{0.83}\right)_{3}$. } \\
\hline $\mathrm{A}$ & $\mathrm{X}_{3}$ & $n_{F T L}<n_{\text {threshold }}$ & $n_{F T L=} n_{\text {threshold }}$ & $n_{F T L}>n_{\text {threshold }}$ & Ref. \\
\hline $\mathrm{MA}$ & $\mathrm{I}$ & 5.23 & 10.81 & 5.07 & {$[2]$} \\
$\mathrm{FA}$ & $\mathrm{I}$ & 18.64 & 19.65 & 4.39 & {$[10]$} \\
$\mathrm{MA}$ & $\mathrm{Br}$ & 9.78 & 10.18 & 10.45 & {$[10]$} \\
$\mathrm{FA}$ & $\mathrm{Br}$ & 8.89 & 10.43 & 22.57 & {$[10]$} \\
$\mathrm{Cs}_{0.17} \mathrm{FA}_{0.83}$ & $\mathrm{Br}_{0.17} \mathrm{I}_{0.83}$ & 4.84 & 16.32 & 8.99 & {$[11]$}
\end{tabular}




\section{References (Supporting Information)}

[1] M. A. Green, Y. Jiang, A. M. Soufiani, A. Ho-Baillie, J. Phys. Chem. Lett. 2015, 6, 4774.

[2] C.-W. Chen, S.-Y. Hsiao, C.-Y. Chen, H.-W. Kang, Z.-Y. Huang, H.-W. Lin, J. Mater. Chem. A 2015, 3, 9152.

[3] J. M. Ball, S. D. Stranks, M. T. Hörantner, S. Hüttner, W. Zhang, E. J. W. Crossland, I. Ramirez, M. Riede, M. B. Johnston, R. H. Friend, H. J. Snaith, Energy Environ. Sci. 2015, 8, 602.

[4] R. E. Treharne, A. Seymour-Pierce, K. Durose, K. Hutchings, S. Roncallo, D. Lane, J. Phys.: Conf. Ser. 2011, 286, 012038.

[5] M. Anaya, J. P. Correa-Baena, G. Lozano, M. Saliba, P. Anguita, B. Roose, A. Abate, U. Steiner, M. Grätzel, M. E. Calvo, A. Hagfeldt, H. Míguez, J. Mater. Chem. A 2016, 4, 11214. [6] Q. Lin, A. Armin, R. C. R. Nagiri, P. L. Burn, P. Meredith, Nat. Photonics 2014, 9, 106. [7] P. Löper, M. Stuckelberger, B. Niesen, J. Werner, M. Filipič, S.-J. Moon, J.-H. Yum, M. Topič, S. De Wolf, C. Ballif, J. Phys. Chem. Lett. 2015, 6, 66.

[8] X. Ziang, L. Shifeng, Q. Laixiang, P. Shuping, W. Wei, Y. Yu, Y. Li, C. Zhijian, W.

Shufeng, D. Honglin, Y. Minghui, G. G. Qin, Opt. Mater. Express 2015, 5, 29.

[9] Y. Jiang, I. Almansouri, S. Huang, T. Young, Y. Li, Y. Peng, Q. Hou, L. Spiccia, U.

Bach, Y.-B. Cheng, M. A. Green, A. Ho-Baillie, J. Mater. Chem. C 2016, 4, 5679.

[10] P. F. Ndione, Z. Li, K. Zhu, J. Mater. Chem. C 2016, 4, 7775.

[11] S. Manzoor, J. Häusele, K. A. Bush, A. F. Palmstrom, J. Carpenter, Z. J. Yu, S. F. Bent, M. D. Mcgehee, Z. C. Holman, Opt. Express 2018, 26, 27441.

[12] Xing, N. Mathews, S. S. Lim, N. Yantara, X. Liu, D. Sabba, M. Grätzel, S. Mhaisalkar, T. C. Sum, Nat. Mater. 2014, 13, 476. 